Intra- and intersexual interactions shape microbial community dynamics in the rhizosphere of Populus cathayana females and males exposed to excess $\mathrm{Zn}$

\title{
Liu, Miao
}

2021-01-15

Liu , M , Wang , Y , Liu , X , Korpelainen , H \& Li , C 2021 , ' Intra- and intersexual interactions shape microbial community dynamics in the rhizosphere of Populus cathayana females and males exposed to excess $\mathrm{Zn}$ ' , Journal of Hazardous Materials, vol. 402 , 123783 . https://doi.org/10.1016/j.jhazmat.2020.123783

http://hdl.handle.net/10138/323974

https://doi.org/10.1016/j.jhazmat.2020.123783

cc_by_nc_nd

acceptedVersion

Downloaded from Helda, University of Helsinki institutional repository.

This is an electronic reprint of the original article.

This reprint may differ from the original in pagination and typographic detail.

Please cite the original version. 
2

3 Intra- and intersexual interactions shape microbial community dynamics in the rhizosphere of Populus cathayana females and males exposed to excess $\mathrm{Zn}$

5

6

7

$9 \quad{ }^{1}$ College of Life and Environmental Sciences, Hangzhou Normal University, Hangzhou

10

11

12

13

14

15

16

17

18

19

20

21

22

$$
\text { Miao Liu }{ }^{1} \text {, Yuting Wang }{ }^{1} \text {, Xiucheng Liu }{ }^{1} \text {, }
$$

Helena Korpelainen ${ }^{2}$, Chunyang $\mathrm{Li}^{1, *}$
311121, China

${ }^{2}$ Department of Agricultural Sciences, Viikki Plant Science Centre, P.O. Box 27, FI00014 University of Helsinki, Finland

${ }^{*}$ Corresponding author: Chunyang Li

E-mail address: licy@hznu.edu.cn, tel: 86-571-28860063, fax: 86-571-28865333 6 8 9 20 21 22 
Abstract Although increasing attention has been paid to rhizospheric bacteria in plants in relation to the bioavailability and tolerance of heavy metals, interactive effects between sex and microbiological processes on phytoextraction have been overlooked, especially in dioecious plants. In this study, we intended to investigate the responses of rhizospheric bacterial communities of Populus cathayana Rehder to excess Zn under different planting patterns. The results suggested that intersexual and intrasexual interactions strongly affect plant growth and $\mathrm{Zn}$ extraction in both sexes, as well as rhizosphere-associated bacterial community structures. Females had a higher capacity of $\mathrm{Zn}$ accumulation and translocation than males under all planting patterns. Males had lower $\mathrm{Zn}$ accumulation and translocation under intersexual than under intrasexual interaction; the contrary was true for females. Females harbored abundant Streptomyces and Nocardioides in their rhizosphere, similarly to males under intersexual interaction, but differed from single-sex males under excess Zn. Conversely, intersexual interaction increased the abundance of key taxa Actinomycetales and Betaproteobacteria in both sexes exposed to excess $\mathrm{Zn}$. Males improved the female rhizospheric microenvironment by increasing the abundance of some key tolerance taxa of Chloroflexi, Proteobacteria and Actinobacteria in both sexes under excess $\mathrm{Zn}$ in intersexual interaction. This was associated with metal activation and bioavailability. Females harbored abundant Methanothermobacter, while males had abundant Mycobacterium in their rhizosphere under intrasexual interaction. These results indicated that the sex of neighboring plants affected sexual differences in the choice of specific bacterial colonizations for phytoextraction and tolerance to $\mathrm{Zn}$-contaminated 
soils, which might regulate the spatial segregation and phytoremediation potential of $P$. cathayana females and males under heavy metal contaminated soils.

Key words: sexual interaction; excess Zn; bacterial abundance; bacterial community; rhizosphere.

\section{Graphical abstract}

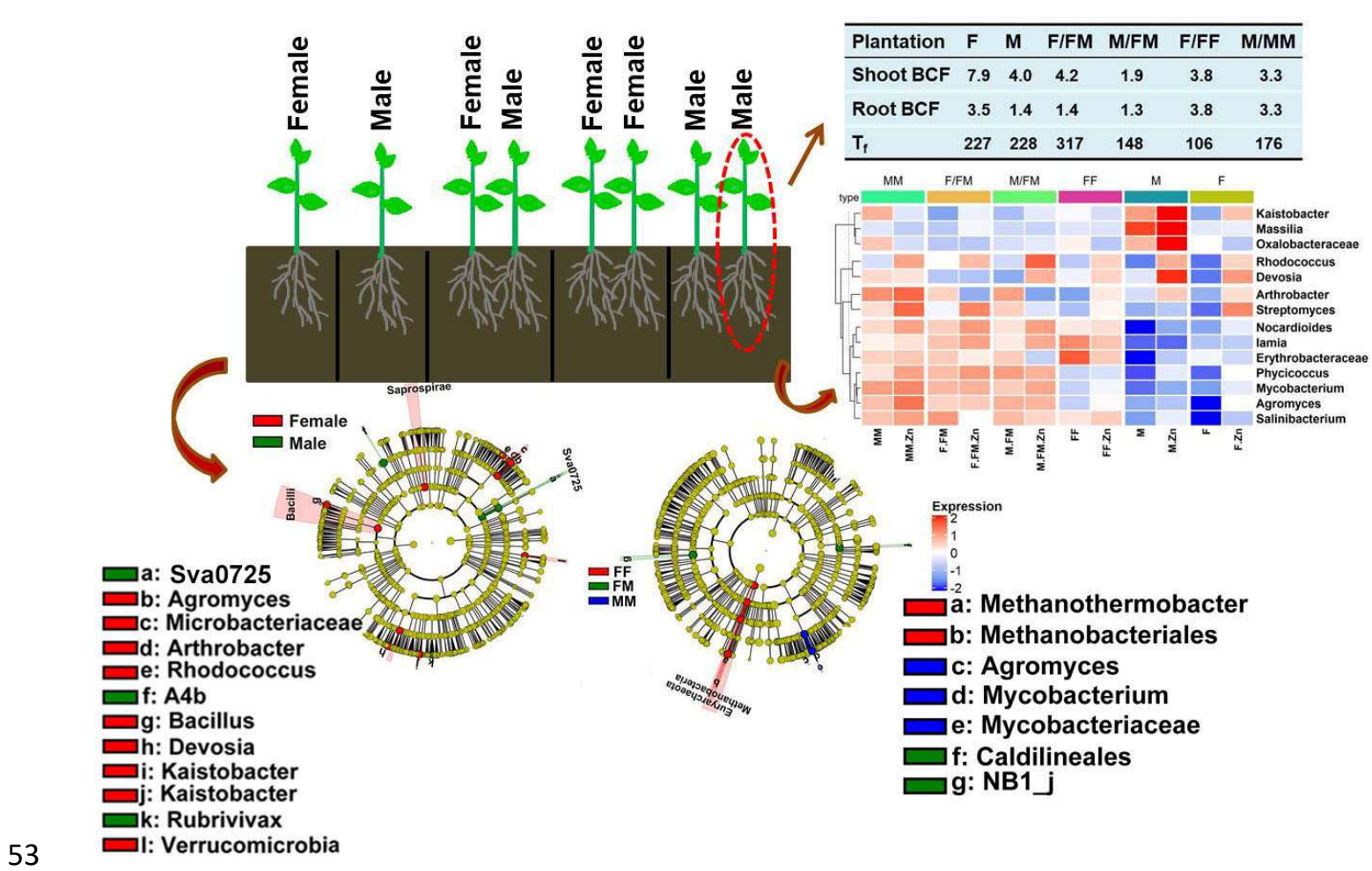




\section{Introduction}

Males and females of dioecious plant species differ in their sexual and vegetative traits, including physiology, phenology, and allocation to reproduction and defense (Chen et al., 2014; Tonnabel et al., 2017; Xia et al., 2020). Sex-related differences in these traits are probably associated with differences in reproductive costs. Females allocate more resources to reproduction than males, since females produce not only flowers but also fruits and seeds (Juvany and Munné-Bosch, 2015). The maintenance of reproductive vigor usually limits vegetative growth and defense investment. Thus, when resources are limited, reproduction directly competes with the other two processes, leading to reduced stress tolerance (Mercer and Eppley, 2010; Tonnabel et al., 2017). It has been shown that females generally allocate more resources to reproduction and males often increase investment into defensive responses under natural conditions (Juvany and Munné-Bosch, 2015). Our previous studies have suggested that males usually exhibit a higher tolerance to stressful environments when compared with females (Zhao et al., 2012; Chen et al., 2014; Li et al., 2016; Zhang et al., 2019).

Zinc $(\mathrm{Zn})$ is an essential micronutrient with a series of critical roles in living organisms; yet, $\mathrm{Zn}$ can be toxic at elevated concentrations (Broadley et al., 2007; Lu et al., 2013). It has been suggested that $\mathrm{Zn}$ toxicity symptoms usually appear when the leaf $\mathrm{Zn}$ content is $>30 \mathrm{mg} \cdot \mathrm{kg}^{-1}$ of leaf dry weight, although the toxicity threshold may be highly variable, even in the same species (Ayangbenro and Babalola, 2017). Excess Zn affects 
plant growth and development, as well as threatens the health of animals due to excessive amounts of $Z n$ ending up into the food chain (Duruibe et al., 2007; Carruthers, 2016). The threat of excess $\mathrm{Zn}$ to the health of living organisms in the environment is exacerbated by its persistent nature (Ayangbenro and Babalola, 2017). Therefore, it is critical to remediate Zn-polluted soils. Several fast-growing trees, including poplars, are regarded as promising candidates for phytoremediation of heavy metal-polluted soils due to their high photoabsorption capacity and biomass, as well as reduced impact on the food chain (Chen et al., 2011; He et al., 2015; Li et al., 2017).

The migration and transformation of heavy metals in rhizospheric soils largely depend on the physical and chemical properties of soil (Rasmussen et al., 2000; Weng et al., 2014), plant types (Hou et al., 2017), rhizospheric microorganisms (Ayangbenro and Babalola, 2017) and exudates (Tao et al., 2020). Among these, rhizospheric microbial interactions with heavy metals play a critical role in heavy metal uptake and tolerance (Rajkumar et al., 2012). Microorganisms have developed variable mechanisms for maintaining heavy metal homeostasis and resistance, including biomineralization, bioaccumulation, biotransformation and biosorption (Navarro-Noya et al., 2010; Mishra et al., 2017). Heavy metals have been shown to suppress microorganisms' growth, and alter their cell morphology and biochemical characteristics, which reduces microbial biomass and diversity (Ayangbenro and Babalola, 2017). Still, microorganisms have evolved diverse defense mechanisms that help them cope with the toxic effect of heavy metals. Burd et al. (2000) have suggested that a metal-resistant 
bacterium Kluyvera ascorbate SUD 165 alleviates growth inhibition caused by a high level of nickel in Brassica campestris. Hou et al. (2017) have also reported that the rhizospheric bacterium Streptomyces probably promotes $\mathrm{Cd}$ accumulation in the hyperaccumulator plant Sedum alfredii. Therefore, the coexistence of plant and microbial systems not only facilitates survival in heavy-metal contaminated soils, but also the removal of heavy metal.

Interspecific and/or intraspecific neighbor interactions of plants play critical roles in determining the structure and function of biological communities (Chen et al., 2014). Intra- and interspecific competitive capacities have important implications for phytoremediation in metal-hyperaccumulating species (Arthur et al., 2005; Pilon-Smits and Freeman, 2006). Interactions have been shown to alter plants' responses to nickel and Zn (Koelbener et al., 2008). Zhao et al. (2017) have found that interspecific interactions can enhance antioxidant enzyme activities that increase survival and fitness in plants exposed to multiple metal stresses. Chen et al. (2016) have also shown that resource competition between consexual and heterosexual neighboring plants affect $\mathrm{Cd}$ allocation, biomass partitioning and carbon-nutrient balance in poplars exposed to $\mathrm{Cd}$ stress. Interactions not only alter plants' morphological and physiological responses, such as nutrient uptake, heavy metal availability and root exudate secretion, but also affect microbial communities in soil (Guo et al., 2019). So far, the effects of intersexual and intrasexual interactions on belowground microbial communities have been largely overlooked, especially under heavy metal stress. 
122 Populus cathayana Rehder is widely distributed in China and is regarded as a major

123 forestry species with a high commercial and ecological value. P. cathayana is a 124 common dioecious plant that displays sexual dimorphism (Chen et al., 2014; Zhang et 125 al., 2019; Xia et al., 2020). Recently, some studies have suggested that poplar species 126 have different tolerance mechanisms and phytoremediation potential to heavy metals, 127 mainly based on genetic differences (Chen et al., 2017; Bi et al., 2020; Liu et al., 2020b). 128 In addition, Populus females and males display sexually different physiological 129 responses to heavy metal stress, and males usually show a stronger tolerance when 130 compared to females (Chen et al., 2016, 2017; Liu et al., 2020a, b). Sex-specific 131 responses to abiotic factors are affected by inter- and/or intraspecific interactions (Chen 132 et al., 2016, 2017). However, sex-specific responses to excess $\mathrm{Zn}$ stress and neighbor 133 effects have been largely overlooked in $P$. cathayana, especially in relation to 134 rhizospheric microbial community structures. In the present study, $P$. cathayana was 135 used to examine sexual differences in competitive ability under excess $\mathrm{Zn}$ conditions. 136 We aimed to address the following questions: (i) Does excess $\mathrm{Zn}$ affect intra- and 137 intersexual interactions? (ii) How do intra- and intersexual interactions affect 138 rhizospheric bacterial communities? (iii) Do interactive effects between excess $\mathrm{Zn}$ and 139 sexual interactions affect plant growth and rhizospheric bacterial community $140 \quad$ composition and diversity? 
143

144

145

\subsection{Plant materials and experimental design}

Cutting of $P$. cathayana females and males were collected from 60 different trees sampled in 15 populations in the riparian and valley flat habitats of the Qinghai Province, China. Cuttings were rooted as described by Chen et al. (2016). The experimental design was completely randomized with three factors (sex, excess $\mathrm{Zn}$ and plantation type), i.e. two sexes (females, males), two $\mathrm{Zn}$ regimes (no- $\mathrm{Zn}, \mathrm{Zn}$ ) and five plantation types. After sprouting and growing for 4 weeks, uniform seedlings were planted into 60 -L plastic pots filled with $c .40 \mathrm{~kg}$ of homogenized soil. The soil was collected from the poplar plantation at the Hangzhou Normal University, Zhejiang Province, China (30.03' N, 120.12'E). Soil samples were air-dried and sieved through $2 \mathrm{~mm}$ sieve. The properties were as follows: $1.77 \mathrm{~g} \mathrm{~kg}^{-1}$ total $\mathrm{N}, 1.80 \mathrm{~g} \mathrm{~kg}^{-1}$ total $\mathrm{P}, 7.91$ $\mathrm{g} \mathrm{kg}^{-1}$ total $\mathrm{K}$, and $0.1 \mathrm{~g} \mathrm{~kg}^{-1}$ total $\mathrm{Zn}$. For the excess $\mathrm{Zn}$ treatment, $1 \mathrm{~L}$ deionized water containing $100 \mu \mathrm{M} \mathrm{ZnSO}_{4}$ was used to evenly irrigate the pots every two days until the final $\mathrm{Zn}$ level of $50 \mathrm{mg} \mathrm{ZnSO}_{4} \mathrm{~kg}^{-1}$ dry soil was reached, while the control plants were irrigated with equal quantities of deionized water (Chen et al., 2016).

The five plantation types were as follows: F, single-cultivated females; M, singlecultivated males; FF, female $\times$ female; MM, male $\times$ male; FM, female $\times$ male. Intrasexual neighboring plants were denoted as $\mathrm{M} / \mathrm{MM}$ for males and $\mathrm{F} / \mathrm{FF}$ for females. Intersexual neighboring plants were denoted as $\mathrm{M} / \mathrm{FM}$ for males and F/FM for females. For single-plant cultivation, one cutting was planted per pot (a female or a male); for 
interactions, two plants (two females, two males or a female and a male) were cultivated $10 \mathrm{~cm}$ apart from each other in a plastic pot (external diameter $52 \mathrm{~cm}$ and height 35 $\mathrm{cm})$. All pots were arranged randomly and each treatment was replicated four times. The experiment was performed at the Hangzhou Normal University. The plants were cultured for $120 \mathrm{~d}$ in a semi-controlled greenhouse at the Hangzhou Normal University (China, $30.03^{\prime} \mathrm{N}, 120.12^{\prime} \mathrm{E}$ ) with a relative humidity of $76 \%-81 \%$, a daytime temperature of $21-25^{\circ} \mathrm{C}$, a night-time temperature of $15-18{ }^{\circ} \mathrm{C}$ and a photoperiod of 12-14 h throughout the growth period.

\subsection{Gas exchange and fluorescence measurements}

The fully developed young leaves from each plant were used to measure gas exchange and chlorophyll fluorescence. Net $\mathrm{CO}_{2}$ assimilation rate $(A)$ and stomatal conductance $\left(g_{\mathrm{s}}\right)$ were measured with a portable photosynthesis measuring system (L1-6400), as described previously by Chen et al. (2011). Chlorophyll fluorescence kinetics parameters (ETR, electron transport rate; quantum yield of photochemical energy conversion in PS II, Y(II); quantum yield of regulated non-photochemical energy loss in $P S I I, Y(N P Q) ; F_{\mathrm{v}} / F_{\mathrm{m}}$, variable and maximum fluorescence) were measured with a PAM chlorophyll fluorometer (PAM 2100, Walz, Effeltrich, Germany). These parameters were calculated according to the method of Van Kooten and Snel (1990).

\subsection{Soil sampling, plant harvesting and element measurements}


188 After the measurement of photosynthesis, rhizosphere soil was collected by gently 189 shaking a plant root; the soil adhering to the root was collected as a sample of 190 rhizospheric soil. In total, 40 soil samples $(4$ replicates $\times 5$ interaction patterns $\times 2$ 191 treatments) were immediately sieved $(4 \mathrm{~mm})$ in the laboratory. The rhizospheric soils 192 were divided into two subsamples. One subsample was oven dried at $75^{\circ} \mathrm{C}$ and used 193 for analyzing soil properties, and another subsample was stored at $-80{ }^{\circ} \mathrm{C}$ until DNA extraction.

The plants were separated into leaves, stems and roots, and washed with deionized water. Dried leaves and roots were finely ground, and about $0.4 \mathrm{~g}$ samples $(<1 \mathrm{~mm})$ were dissolved in 3:1 (v/v) of $\mathrm{HNO}_{3}$ and $\mathrm{HClO}_{4}$. The mixtures were carefully shaken and predigested at room temperature for $30 \mathrm{~min}$. The vessels used for digestion were sealed and placed into a microwave digestion system. The microwave heating program was performed as follows: (1) $10 \mathrm{~min}$ at $170{ }^{\circ} \mathrm{C}$; (2) $10 \mathrm{~min}$ at $190{ }^{\circ} \mathrm{C}$; (3) $10 \mathrm{~min}$ at $210{ }^{\circ} \mathrm{C}$ (Tokalığlu et al., 2018). The vessels were cooled down to room temperature to avoid splashing and foaming. Clear digested solutions were transferred to $25 \mathrm{ml}$ polyethylene tubes, which were filled to a volume of $25 \mathrm{ml}$ with ultra-pure water for further ICP-MS analysis. Total Zn and nutrient elements were measured with ICP-MS (inductively coupled plasma mass spectrometer; Agilent 7500a; Agilent Technologies).

207 For quality assurance/quality control (QA/QC) purposes, a blank control and standard reference material GBW10020 (GSB-11) of citrus leaves were used to validate quantification according to Xie et al. (2020). Blank control and reference materials were 
treated under the same conditions as the experimental samples. The recovery of the standard at a medium calibration level was checked with every 10 samples. The method detection limits $\left(\mathrm{mg} \mathrm{kg}^{-1}\right)$ were $0.2 \mathrm{mg} \mathrm{l}^{-1}$ for $\mathrm{Zn}$ and the recovery rates were $80-90 \%$. All data are presented as means \pm the standard deviations, unless specified differently.

The translocation factor $\left(T_{\mathrm{f}}\right)$ was defined as the $\mathrm{Zn}$ concentration in a shoot divided by the $\mathrm{Zn}$ concentration in roots (He et al., 2013b). The bio-concentration factor BCF was calculated as the $\mathrm{Zn}$ concentration in roots or shoots divided by the $\mathrm{Zn}$ concentration in the soil (Shi et al., 2010; He et al., 2013b).

\subsection{Statistical analysis}

Statistical analyses were carried out using the SPSS software package (version 22.0). All data were checked for normality before analyses of variance (ANOVAs). Differences between means were analyzed by Duncan's tests following three-way ANOVAs, which were used to evaluate sexual interaction and excess $\mathrm{Zn}$ treatment effects.

\subsection{DNA extraction, 16S amplification and MiSeq sequencing}

Approximately $0.5 \mathrm{~g}$ of each soil sample was used to extract genomic DNA utilizing the PowerSoil DNA Isolation Kit (MoBio Laboratories, Inc. Carlsbad, USA) following 
the manufacturer's instructions. The 16S rRNA genes were amplified using the primer pair 515F (5'-GTGCCAGCMGCCGCGGTAA-3') and 806R (5'GGACTACHVGGGTWTCTAAT-3'). Approximately $10 \mathrm{ng}$ of purified DNA was amplified with $25 \mu 1$ of the PCR reaction system under the following conditions: at $95{ }^{\circ} \mathrm{C} 2 \mathrm{~min}$ for denaturation, followed by 40 cycles of $10 \mathrm{~s}$ at $95{ }^{\circ} \mathrm{C}$ for denaturation, $30 \mathrm{~s}$ at $56^{\circ} \mathrm{C}$ for annealing, and $20 \mathrm{~s}$ at $72{ }^{\circ} \mathrm{C}$ for extension, with 55 to $95^{\circ} \mathrm{C}$ for melting curve analyses. The PCR products were pooled and purified with a MicroElute CyclePure Kit (Omega), and high-throughput sequencing was performed using the Hiseq 2500 PE250 platform with $2 \times 250 \mathrm{bp}$ according to the manufacturer's manual.

\subsection{Processing of high-throughput sequencing data and analysis}

Amplicon sequences were processed using the QIIME 2 version 2017.12 (https://qiime2.org/). All sequences of 16S rRNA raw data were demultiplexed, and quality control was carried out using DADA2 with the "consensus" method, to remove chimeric and low-quality sequences (Callahan et al., 2017; Yuan et al., 2018). When the paired-ends were joined, the unreliable and low-quality sequences were detected based on the low sequence quality of the $3^{\prime}$-ends of the reads (Merloti et al., 2019). After that, the Amplicon Sequence Variants (ASVs) were created using the Deblur tool. The resulting final ASV table contained only high-quality reads. The taxonomic identification of ASVs (with $99 \%$ of similarity) was conducted with the VSEARCH consensus taxonomy classifier implemented in Qiime2 and the SILVA 16S rRNA 
database. The archaeal and chloroplast sequences were removed. Statistical analyses of the 16S rRNA microbiome sequencing data were performed using the generated taxonomic matrices. The sequencing data were submitted to NCBI (BioProject accession number: PRJNA644210).

\subsection{Statistical analysis of sequencing data}

The $\alpha$-diversity of bacteria was characterized by the Simpson's diversity index and the effective number of species, and the data were analyzed with ANOVA using Duncan's test $(P<0.05)$. $\beta$-diversity was calculated based on weighted-UniFrac distance metrics.

Principal coordinates analysis (PCoA) was used to separate the overall bacterial community structure based on the weighted-UniFrac distance with the "pcoa" function of the "ape" package in R (v3.2.2). Permutational multivariate analysis of variance (PERMANOVA) was performed to separate and evaluate the effects of sex, plantation mode and $\mathrm{Zn}$ treatment and theirinteractions on the rhizospheric bacterial communities using the "anosims" function in "vegan" package in R (v3.2.2). The linear discriminant analysis (LDA) effect size (LEfSe) algorithm was used to analyze the relative bacterial abundance in different treatments, irrespective of sexual interactions (Class: $\mathrm{Zn}$ treatment; Subclass: interaction patterns), as well as in different sexual interaction patterns irrespective of $\mathrm{Zn}$ treatment (Class: sexual interaction; Subclass: Zn treatment). The online Galaxy application (version 1.0) was used with a threshold of 1.0 and a Wilcoxon $P$-value of 0.05 (http://huttenhower.sph.harvard.edu/galaxy/). A similarity 
percentage (SIMPER) analysis was performed with the PRIMER 6 software to find differences between sexual interaction patterns and other treatments. The OTUs less than $1 \%$ of the relative abundance were discarded from the analysis according to Marasco et al. (2018). Correlation coefficients between the bacterial abundance at the phyla level and Zn amount were obtained with python (SciPy package). The heatmap of correlation coefficients was plotted with $\mathrm{R}$ (Heatmap package).

\subsection{PICRUSt functional prediction}

The PICRUSt (phylogenetic investigation of communities by reconstruction of unobserved states, v1.0.0) pipeline was used to predict the relative abundance of gene transcripts in bacteria. The pick_closed_reference_otus.py script in QIIME (similarity threshold, 0.97) was used to cluster sequences into OTUs. The OTUs were first normalized by the copy number by removing the copy number of the $16 \mathrm{~S}$ marker gene.

The Nearest Sequenced Taxon Index (NSTI) and KEGG Ortholog (KO) were obtained by the predict_metagenomes.py script. The KO level 3 within the pathway hierarchy of KEGG was collapsed using the categorize_by_function.py script (Langille et al., 2013; Hou et al., 2017). The predicted metagenomes were then annotated using the KEGG database, and the predicted relative abundances of gene transcripts for selected pathways associated with bacterial functions were analyzed and plotted using STAMP (Parks et al. 2014; Hou et al. 2017).

\section{Results}




\subsection{Plant growth and Zn phytoextraction}

Under control conditions (no excess $\mathrm{Zn}$ ), males showed $21 \%$ and $48 \%$ higher $\mathrm{CO}_{2}$ assimilation rate $(A)$ and stomatal conductivity $\left(g_{\mathrm{s}}\right)$ respectively, than females under single-plant cultivation (Table 1). Females had lowest $A$ and $g_{\mathrm{s}}$ under intersexual interaction (F/FM)under control conditions (Table 1). Compared with controls, $A$ and $g_{\mathrm{s}}$ decreased by $29 \%$ and $18 \%$, respectively, in females and by $19 \%$ and $22 \%$, respectively, in males in single-sex cultivation under excess Zn (Table 1). Excess Zn decreased $A$ by $18 \%, 11 \%, 12 \%$ and $16 \%$, and $g_{s}$ by $20 \%, 22 \%, 32 \%$ and $57 \%$, in F/FM, $\mathrm{M} / \mathrm{FM}$ (males in intersexual interaction), F/FF (females in intrasexual interaction) and $\mathrm{M} / \mathrm{MM}$ plants (males in intrasexual interaction), respectively (Table 1). In addition, excess Zn conditions (Table 1).

Excess $\mathrm{Zn}$ treatment decreased $F_{\mathrm{v}} / F_{\mathrm{m}}, E T R$ and $Y$ (II) by $6 \%, 37 \%$ and $50 \%$, respectively, in females and by $4 \%, 17 \%$ and $8 \%$, respectively, in males under singlesex cultivation (Table 1). Sexual interactions did not affect $F_{\mathrm{v}} / F_{\mathrm{m}}$ in either sex under control conditions (Table 1). Excess $\mathrm{Zn}$ did not affect $F_{\mathrm{v}} / F_{\mathrm{m}}$ and $E T R$ in males (M/MM) and females $(\mathrm{F} / \mathrm{FF})$ when compared with controls. However, $F_{\mathrm{v}} / F_{\mathrm{m}}, E T R$ and $Y(I I)$ were 4\%, 37\% and 54\% higher, respectively, in M/FM plants than in F/FM plants under excess $\mathrm{Zn}$, and $Y$ (II) of males was $13 \%$ higher when compared to females under 
intrasexual interaction (Table 1). In addition, excess $\mathrm{Zn}$ treatment increased $Y(N P Q)$ by $71 \%$ in females, but not in males, under single-plant cultivation (Table 1) when compared to control conditions. Sexual interactions did not affect $Y(N P Q)$ in either sex under control conditions. However, excess $\mathrm{Zn}$ increased $Y(N P Q)$ by $32 \%, 58 \%$ and $14 \%$ in F/FM, F/FF and M/MM, respectively, when compared to controls (Table 1).

Excess $\mathrm{Zn}$ increased the $\mathrm{Zn}$ content in by 22.9- and 4.3-fold, respectively, in leaves, by 3.1- and 1.4-fold, respectively, in shoots, and by 2.7- and 3.2-fold, respectively, in roots of females and males under single-sex cultivation (Fig. 1). Under excess $\mathrm{Zn}$ conditions, Zn levels increased by 4.6-, 29.6-, 13.6- and 13.1-fold, respectively, in leaves, by $97 \%, 300 \%, 327 \%$ and $219 \%$, respectively, in stems, and by $160 \%, 240 \%, \%$ and $160 \%$, respectively, in roots of $\mathrm{F} / \mathrm{FM}, \mathrm{M} / \mathrm{FM}, \mathrm{F} / \mathrm{FF}$ and $\mathrm{M} / \mathrm{MM}$ when compared to controls (Fig. 1). Under excess $\mathrm{Zn}$, the $\mathrm{Zn}$ level of females was $37 \%$ and $39 \%$ higher in leaves and roots, respectively, but $82 \%$ lower in stems when compared to males in single-sex cultivation under excess $\mathrm{Zn}$ conditions. The leaf and stem $\mathrm{Zn}$ levels of males were lower than those of females under intersexual interaction; the contrary was true for intrasexual interaction under excess $\mathrm{Zn}$ (Fig. 1). In addition, there was no difference in root $\mathrm{Zn}$ concentrations between sexes under intersexual interaction, whereas the $\mathrm{Zn}$ level in roots of $\mathrm{M} / \mathrm{MM}$ was $26 \%$ lower than that of $\mathrm{F} / \mathrm{FF}$ plants.

Females had higher $T_{\mathrm{f}}$ (the ratio of $\mathrm{Zn}$ in the shoots to roots) than males under singlesex cultivation. $T_{\mathrm{f}}$ was higher in both sexes under single-sex cultivation than under 
342

intersexual interactions (except for F/FF) when exposed to excess Zn (Fig. 1). F/FM had highest $T_{\mathrm{f}}$ and F/FF showed the lowest $T_{\mathrm{f}}$ among all excess $\mathrm{Zn}$ treatments (Fig. 1). Under excess $\mathrm{Zn}, \mathrm{M} / \mathrm{MM}$ showed $16 \%$ higher $T_{\mathrm{f}}$ than M/FM. In single-sex cultivations under excess $\mathrm{Zn}$, females had $141 \%$ and $98 \%$ increases, respectively, in root BCF (the ratio of $\mathrm{Zn}$ in the roots to soil) and shoot $\mathrm{BCF}$ (the ratio of $\mathrm{Zn}$ in the shoots to soil) when compared to males. F/FF had highest root BCF among all excess Zn treatments. Root and shoot $\mathrm{BCF}$ values were $48 \%$ and $72 \%$ higher, respectively, in $\mathrm{M} / \mathrm{MM}$ than in $\mathrm{M} / \mathrm{FM}$ under excess $\mathrm{Zn}$, while females had 1.2-fold higher shoot $\mathrm{BCF}$ than males under intersexual interaction with excess $\mathrm{Zn}$ (Fig. 1).

\subsection{Dominant taxa of bacterial communities}

The bacterial communities predominantly consisted of Proteobacteria (33\%), Actinobacteria (17\%), Acidobacteria (16\%), Chloroflexi (14\%), Planctomycetes (6\%), Bacteroidetes (4\%), Gemmatimonadetes (2\%), Crenarchaeota (2\%), Verrucomicrobia (1\%), and Nitrospirae (1\%). These dominant species were affected by plant interactions and excess Zn (Fig. 2). Excess Zn reduced the relative abundance of the Proteobacteria phylum in the rhizosphere of $\mathrm{M} / \mathrm{MM}$ and FM, but did not affect Proteobacteria in the rhizosphere of F/FF. Excess $\mathrm{Zn}$ reduced the abundance of Actinobacteria and Planctomycetes phyla in both sexes under intersexual interactions. The relative abundance of Proteobacteria and Actinobacteria phyla were higher under the excess $\mathrm{Zn}$ treatment than under control conditions in both sexes when plants were cultivated alone, 
while the contrary was true for the Chloroflexi phylum (Fig. 2).

\subsection{Bacterial community diversity and structure}

The alpha-diversities of bacterial communities (effective numbers of species) were compared in females and males under different plantation modes and excess $\mathrm{Zn}$ treatments. As shown in Fig. 3, intra- and intersexual interaction affected bacterial community structures, but the effects of these interaction patterns were greater under excess Zn. Permutational multivariate analysis of variance (PERMANOVA) further demonstrated that plantation modes were the largest source of variation $(25.16 \%, P<$ 0.001; Table 2). The $\mathrm{Zn}$ levels were the second largest source of variation $(5.00 \%, P<$ 0.004; Table 2).

\subsection{Taxonomic composition of bacterial communities}

The linear discriminant analysis (LDA) effect size analysis (LEfSe) was performed to compare the bacterial composition from phyla to genera between $\mathrm{Zn}$ treatments, as well as between sexes (Fig. 4). We found that bacterial compositions showed significant differences among sexual interaction patterns and $\mathrm{Zn}$ treatments. The orders Acidimicrobiales, Micromonosporaceae, RB40, Verrucomicrobiales, Thiotrichales, MND1, Piscirickettsiaceae and Pirellulaceae were predominant under excess Zn, while the genera Pontibacter, Chryseobacterium, Lysobacter, Kaistobacter and Massilia, and 
386

387

the class Flavobacteria were enriched in plants without excess $\mathrm{Zn}$ under single cultivation (Fig. 4a). Moreover, the order Sva0725, the family A4b and the genus Rubrivivax were dominant in the rhizosphere of males, while other taxa were enriched in soil with females (Fig. 4b).

In sexual interaction experiments, the order Nitrososphaerales was generally more abundant in the soil of control plants (Fig. 4c). Under excess Zn, the class Saprospirae, the orders GCA004, Solirubrobacterales and AKYG1722, the families AKIW874, Cellulomonadaceae, Mycobacteriaceae and Sporichthyaceae, and the genera Bacillus, Rhodoplanes and Mycobacterium were predominant (Fig. 4d). Irrespective of the $\mathrm{Zn}$ treatment, the genera Agromyces and Mycobacterium, as well as the family Mycobacteriaceae were abundant in the soil of M/MM, whereas the order Methanobacteriales and the genus Methanothermobacter were more abundant in the soil of F/FF under intrasexual interaction (Fig. 4d). In contrast, orders Caldilineales and NB1-j were more prevalent in the soil of FM exposed to intersexual interaction (Fig. 4d).

\subsection{Functional predictions of bacterial communities}

The PICRUSt analysis was performed to predict the metagenome gene functions. As shown in Fig. 5, the PICRUSt analysis suggested that the predicted differential gene abundances between treatments were related to carbohydrates, amino acids, lipids and 
secondary metabolism in the rhizosphere of females and males under single-plant cultivation. When compared to females under single-plant cultivation, males had a higher abundance of predicted genes involved in the citrate cycle and carotenoid biosynthesis in the rhizosphere in control conditions (Fig. 5a). Excess Zn stress reduced arachidonic acid metabolism, flavonoid biosynthesis and peptidoglycan, and increased the abundance of predicted genes related to glycolysis, citrate cycle and leucine synthesis in females under single-plant cultivation.

Under plant interactions, the differentially abundant genes in different treatments in the rhizospheres of both sexes were related to amino acid translation, and amino acid and lipolic acid metabolism under single-plant cultivation (Fig. 5b). Excess $\mathrm{Zn}$ reduced the abundance of the predicted genes related to cysteine, methionine and thiamine metabolism, especially in the rhizosphere of females exposed to intrasexual interaction.

However, excess $\mathrm{Zn}$ elevated the abundance of predicted genes related to tyrosine metabolism in the rhizosphere of females, compared to males, both under inter- and intraspecific interaction (Fig. 5b).

\subsection{Relative abundance of key taxa associated with $\mathrm{Zn}$ levels in plants}

We examined the bacterial abundance in the rhizosphere at the genus level in relation to $\mathrm{Zn}$ levels in roots (Fig. 6). First, we examined the relative abundance of taxa positively associated with $\mathrm{Zn}$ levels. Under single-plant cultivation, females showed a 
relatively higher abundance of families Streptomycetaceae and Rhodobacteraceae, and the phylum Chloroflexi than males under an increasing Zn supply in the rhizosphere. In contrast, the increased $\mathrm{Zn}$ level raised the relative abundance of the family Sphingomonadaceae in the rhizosphere of males compared to the female rhizosphere. Under intrasexual interaction, males had a higher relative abundance of the Actinomycetales order and Phyllobacteriaceae family when compared to intersexual interaction (Fig. 6). By contrast, the family Alphaproteobacteria was more abundant in the rhizosphere of males exposed to excess $\mathrm{Zn}$ under intersexual interaction than under intrasexual interaction. In females, the orders Myxococcales, Roseiflexales and Actinomycetales, and the class Betaproteobacteria were predominant in the rhizosphere exposed to intersexual interaction under excess $\mathrm{Zn}$ relative to intrasexual interaction (Fig. 6). The increased abundance of the order Rhizobiales under excess Zn was specific to females exposed to intrasexual interaction relative to intersexual interaction. Under intersexual interaction, the abundance of the order Actinomycetales was higher in males, while the order Rhizobiales was more abundant in the rhizosphere of females under excess Zn (Fig. 6).

Then, we examined the relative abundance of bacteria negatively associated with $\mathrm{Zn}$ levels in roots (Fig. 6b). We found that under excess $\mathrm{Zn}$, the relative abundance of most bacterial classes, such as Planctomycetia, Betaproteobacteria and Acidobacteria-6, were lower in the rhizosphere of females than in that of males under single-sex conditions. When compared to females under single-sex conditions, males had a higher 
452

453

454

455

abundance of the family Hyphomonadaceae and the order WD2101 irrespective of the $\mathrm{Zn}$ application. Under intrasexual interaction with excess $\mathrm{Zn}$, the abundance of the class Gemm-5 in the rhizosphere of males, and the abundance of the genus Planctomyces in females and males were higher than under intersexual interaction (Fig. 6b). On the other hand, under intersexual interaction with excess $\mathrm{Zn}$, the abundance of the RB40 family was higher but the abundance of the genus Planctomyces was lower in the rhizosphere of females than in males.

\section{Discussion}

\subsection{Sexual interactions affect $Z n$ phytoextraction in plants}

Neighbor interactions of plants affect plant growth and community composition (Hodge and Fitter, 2013; Hawkins and Crawford, 2018). In turn, these interactions could be altered by abiotic stress, e.g. heavy metals (Chen et al., 2016, 2017). It has been shown that abiotic stress can alter competitive interactions (Chen et al., 2016, 2017). Selenium has been found to strongly influence plant-plant interactions and play a vital role in elemental allelopathy (El Mehdawi et al., 2011). In this study, under excess Zn stress, F/FM accumulated more $\mathrm{Zn}$ in their leaves and barks compared to F/FF, while males accumulated less under intersexual interaction than under intrasexual interaction (Table 1; Fig. 1). Responses of sexes to abiotic stresses depend mainly on the specific properties of stresses, the soil status and the exposure duration (Howard et al., 2000; 
474

Tonneijck et al., 2004). $\mathrm{Zn}$ is an essential trace element for plants and, in our study, the leaf $\mathrm{Zn}$ levels did not reach the toxic threshold for poplars under any interaction (Fig. 1). Females and males exposed to inter- and intrasexual interaction showed strong tolerance to excess $\mathrm{Zn}$ (Table 1). Interestingly, we found that under intrasexual interaction both females and males accumulated more $\mathrm{Zn}$ in the roots, which largely inhibited $\mathrm{Zn}$ transportation to the shoots and leaves (Fig. 1). The reduced heavy metal accumulation in leaves facilitates heavy metal tolerance in woody plants (He et al. 2013a).

The tolerance of plants to heavy metals is also reflected in leaf photosynthesis (Chandra and Kang, 2016; Salisbury et al., 2018), which indicates the ability of plants to thrive in specific environments, including heavy metal stress(Simkin et al., 2019; Hu et al., 2020). The accumulation of heavy metal in leaves damages photosynthetic electron transport and reduces photosynthesis, which are signs of stress (Aggarwal et al., 2012).

We found that females had higher $\mathrm{Zn}$ enrichment but lower $\mathrm{Zn}$ toxicity tolerance than males under $\mathrm{Zn}$ treatments. The inhibited photosynthesis and electron transmission efficiency were associated with Zn translocation into leaves (Fig. 1; Table 1). Females had higher root-to-shoot translocation under intrasexual than intersexual interaction, as visible as elevated root $\mathrm{BCF}$ but lower $T_{\mathrm{f}}$ under excess $\mathrm{Zn}$ (Fig. 1). However, males favored to accumulate more $\mathrm{Zn}$ in roots, showing higher root $\mathrm{BCF}$ but lower shoot $\mathrm{BCF}$ (Fig. 1). Moreover, females had a higher $\mathrm{Zn}$ translocation efficiency $\left(T_{\mathrm{f}}\right)$ under intersexual than intrasexual interaction, while the contrary was true for males (Fig. 1). 
496

497 subjected to excess $\mathrm{Zn}$ under intersexual interaction. In previous studies, female plants 498 have showed higher competitive ability than males (Mercer and Eppley, 2010; Sánchez-

499 Vilas et al., 2011; Chen et al., 2016). Consistently, we found that females had a stronger 500

501

502

Moreover, the $\mathrm{Zn}$ translocation efficiency was higher in females than in males when competitive ability under excess $\mathrm{Zn}$ even when excess $\mathrm{Zn}$ was toxic for plants. In a previous study, we found that females had a higher expression of genes, such as those from the ZIP family, which facilitate Cd uptake and root-to-shoot translocation in $P$. cathayana (Liu et al., 2020b). Importantly, the potential of females and males for extracting $\mathrm{Zn}$ also depends on underground processes that affect $\mathrm{Zn}$ availability (Fig. 6).

\subsection{Soil microbial composition modified by plantation modes and Zn pollution}

Heavy metals affect rhizosphere-driven microbial community structures (Hou et al., 2017). Soil microorganisms are also critical drivers in modifying community structures and plant-plant interactions (Hodge and Fitter, 2013; Hawkins and Crawford, 2018). The sexually differential trade-off between plant rewards and defense has been shown to influence the colonization of host-specific microbial communities (Bever et al., 2012; Varga et al., 2017). This finding was further demonstrated by our study. We discovered that the bacterial community diversity and richness in the rhizosphere of both sexes were not affected by plantation modes or excess $\mathrm{Zn}$, but probably associated with the planting time and species (Siciliano et al., 2014; Tian and Gao, 2014; Fontana et al., 
518

519

520

521 Generally, heavy metals suppress the growth and abundance of low-resistance microbes

2016). However, the bacterial community structure was strongly affected by plantation modes and $\mathrm{Zn}$ treatments (Fig. 3), which probably affected root $\mathrm{Zn}$ bioavailability.

522 but increase the prevalence of high-resistance bacteria (Pishchik et al., 2016; Wood et al., 2016; Hou et al., 2017). Consistently, the relative abundance of Cytophagales was significantly inhibited by excess $\mathrm{Zn}$ in both sexes, while the abundance of key phyla, such as Betaprteovacteria, Acidoacteria, Nitrosopirales and Proteobacteria, increased under excess $\mathrm{Zn}$ in single-cultivated males (Fig. 4; Figs S1-S2). Interestingly, the abundance of Betaprteovacteria, Acidoacteria, Nitrosopirales and Proteobacteria phyla were positively associated with root Zn levels (Fig. 6), which suggested that they are probably involved in excess $\mathrm{Zn}$ uptake. In addition, we found that when compared to untreated soil, Zn levels in excess Zn-treated soil were 3 7 -fold higher (Fig. S5), and the level was higher than the $\mathrm{Zn}$ toxicity risk screening value for soil (Huang, 2014; Carruthers, 2016). Our results support the view that phytoremediation may be an effective strategy to improve the soil quality by recruiting some beneficial microbes (Ancona et al., 2020). It is evident that if attempting to use microbial remediation of metals, it would be important to investigate further the responses of specific bacterial families.

Sexual interactions alter the structure of root systems and the secretion of root exudates in $P$. cathayana females and males, thus modifying the rhizosphere ecology (Ke and 
Wang, 2020; Xia et al., 2020). The present study found that the Methanotheriales, Mycobacterium and Caldilineales phyla were enriched in the rhizosphere of F/FF, M/MM and FM, respectively (Fig. 4). Among these specific bacteria, the Actinobacteria and Streptomyces phyla have been identified as the most dominant taxa in soils with heavy metal contamination (Watve et al., 2001; Ellis et al., 2003; Alvarez et al., 2017), and they became more abundant under excess $\mathrm{Zn}$ in the rhizosphere of $\mathrm{M} / \mathrm{MM}$ and M/FM (Fig. 4; Figs S3-S4). More importantly, the relative abundance of Actinobacteria showed a positive correlation with root $\mathrm{Zn}$ levels in $\mathrm{M} / \mathrm{MM}$ and FM (Fig. 6). Actinobacteria produce siderophores for $\mathrm{Cd}$ acquisition and protect plants from the invasion of pathogenic bacteria (Viaene et al., 2016). The specific colonization of Actinobacteria in the rhizosphere of Arabidopsis confers a competitive advantage to these plants (Van der Meij et al., 2018). The increased abundance of Actinobacteria following the excess $\mathrm{Zn}$ treatment in the rhizosphere of FM was probably due to $\mathrm{Zn}$ chelation, which was likely the result of a long-term adaptation of sexes to excess $\mathrm{Zn}$ under intersexual interaction. Streptomyces is the largest genus producing antibiotics (Watve et al., 2001; Hong et al., 2009). It has been suggested that some strains belonging to Streptomyces promote metal solubility and auxin synthesis by stimulating siderophore synthesis (Zloch et al., 2016; Hou et al., 2017). Taking into account the higher $\mathrm{Zn}$ accumulation in females under single-sex and intersexual modes (Fig. 1), Streptomycetaceae probably plays a key role in the $\mathrm{Zn}$ accumulation in $P$. cathayana females under excess $\mathrm{Zn}$. 
562

563

564

565

566

567

568

569

570

571

572

573

574

575

576

577

578

579

580

581

582

583

We also found some sex-specific bacterial colonization in the $P$. cathayana rhizosphere under different interaction patterns. The excess $\mathrm{Zn}$ treatment increased the abundance of the phylum Euryarchaeota in both females and males with intrasexual interaction (Figs S3-S4). In addition, the abundances of the phyla Actinobacteria and Chloroflexi were elevated under excess $\mathrm{Zn}$ in the rhizosphere of FM and M/MM (Fig. 4; Figs S3-

S4). Overall, our results suggest that most bacteria prefer to colonize the rhizosphere of both sexes in the case of intersexual interaction, irrespective of $\mathrm{Zn}$ levels, as well as in the rhizosphere of males exposed to intrasexual interaction.

\subsection{Microbial functional prediction highlights the role of sexual interaction patterns}

The PICRUSt analysis suggested that excess $\mathrm{Zn}$ and sexual interactions differentially regulate the abundance of predicted gene transcripts of bacteria in the rhizosphere. The excess $\mathrm{Zn}$ treatment increased the abundance of predicted gene transcripts related to amino acids and organic acids, such as valine, leucine and isoleucine biosynthesis, and the citrate cycle in both sexes under single-plant cultivation, which probably increased organic matter from dead roots, exudates and rhizodeposits (Hou et al., 2017, 2018). It is worth noting that the abundance of predicted gene transcripts related to carotenoid biosynthesis was higher in the rhizospheric bacteria of males than in those of females (Fig. 5a), which probably played an important role in heavy metal tolerance. Excess $\mathrm{Zn}$ increased the abundance of predicted gene transcripts related to tyrosine metabolism and secondary metabolites in males exposed to intersexual interaction and in females 
584

585

under both intra- and intersexual interaction, suggesting that excess $\mathrm{Zn}$ differentially regulates the abundance of predicted gene transcripts. Further studies are needed to explore the relationship between heavy metal stress and gene expression among the bacteria in the rhizospheres of both sexes.

\section{Summary}

This study suggested that excess $\mathrm{Zn}$ and sexual interactions strongly affect $\mathrm{Zn}$ accumulation, and microbial abundance and diversity. Females have higher $\mathrm{Zn}$ accumulation and root-to-shoot translocation under intersexual than under intrasexual interaction combined with excess $\mathrm{Zn}$; the contrary was true for males. Moreover, the plantation modes and excess $\mathrm{Zn}$ treatment altered the bacterial structure of the rhizosphere, which largely affected the $\mathrm{Zn}$ availability and uptake of roots. The $\mathrm{Zn}$ polluted soil with males growing under different interactions promoted some key bacterial taxa related to metal activation and chelation in the rhizosphere, e.g., Actinobacteria and Streptomyces, while the excess Zn-treated soil with females had a lower bacterial abundance under intrasexual interaction than under intersexual interaction. To our knowledge, this is the first study that has showed a possible relationship of $\mathrm{Zn}$ availability with specific bacterial colonization in the rhizosphere of P. cathayana females and males under sexual interactions. Our study provides new 
606

607

608

609

610

611

612

613

614

615

616

617

618

619

620

621

622

623 Conflict of interest The authors declare that they have no conflict of interest.

624

625

626

insight into the interactions among plant sex, plantation types, heavy metal stress and the composition of microbial communities.

Acknowledgements This work was supported by the Talent Program of the Hangzhou

Normal University (2016QDL020).

Author contributions Miao Liu had the main responsibility for data collection, analysis and writing, Yuting Wang and Xiucheng Liu contributed to data collection, Helena Korpelainen contributed to the interpretation of data and manuscript preparation, and Chunyang $\mathrm{Li}$ (the corresponding author) had the overall responsibility for experimental design and project management.

Appendix A. Supplementary data Supplementary material related to this article can be found in the supplementary information. 
627

628

629

630

631

632

633

634

635

636

637

638

639

640

641

642

643

644

645

646

647

\section{References}

Aggarwal, A., Sharma, I., Tripati, B.N., Munjal, A.K., Baunthiyal, M., Sharma, V., 2012.

Metal toxicity and photosynthesis. In: Photosynthesis: overviews on recent progress \& future perspectives. 1st ed. New Delhi: I K International Publishing House Pvt. Ltd; 229-236.

Alvarez, A., Saez, J.M., Davila Costa, J.S., Colin, V.L., Fuentes, M.S., Cuozzo, S.A., Benimeli, C.S., Polti, M.A., Amoroso, M.J., 2017. Actinobacteria: current research and perspectives for bioremediation of pesticides and heavy metals. Chemosphere 166, 4162.

Ancona, V., Caracciolo, A.B., Campanale, C., Rascio, I., Grenni, P., Di Lenola, M., Bagnuolo, G., Uricchio, V.F., 2020. Heavy metal phytoremediation of a poplar clone in a contaminated soil in southern Italy. J. Chem. Technol. Biot. 95, 940-949.

Arthur, E.L., Rice, P.J., Rice, P.J., Anderson, T.A., Baladi, S.M., Henderson, K.L., Coats, J.R., 2005. Phytoremediation - an overview. Critical Rev. Plant Sci. 24, 109-122.

Ayangbenro, A.S., Babalola, O.O., 2017. A New strategy for heavy metal pollutedenvir ornaments: a review of microbial biosorbents. Inter. J. Environ. Public Health 14, 94. 
649

650

651

652

653

654

655

656

657

658

659

660

661

662

663

664

665

666

667 Carruthers, S., 2016. Zinc: deficiency and toxicity. Practical Hydroponics and

668

669

670

Bever, J.D., Platt, T.G., Morton, E.R., 2012. Microbial population and community dynamics on plant roots and their feedbacks on plant communities. Annu. Rev.

Microbiol. 66, 265-283.

Bi, J.W., Liu, X.C., Liu, S.R., Wang, Y.T., Liu, M., 2020. Microstructural and physiological responses to cadmium stress under different nitrogen forms in two contrasting Populus clones. Environ. Exp. Bot. 169, 103897.

Broadley, M.R., White, P.J., Hammond, J.P., Zelko, I., Lux, A., 2007. Zinc in plants. New Phytol. 173, 677-702.

Burd, G.I., Dixon, D.G., Glick, B.R., 2000. Plant growth-promoting bacteria that decrease heavy metal toxicity in plants. Can. J. Microbiol. 46, 237-245.

Callahan, B.J., McMurdie, P.J., Holmes, S.P., 2017. Exact sequence variants should replace operational taxonomic units in marker-gene data analysis. ISME J. 11, 26392643.

Greenhouses 172, 42.

Chandra, R., Kang, H., 2016. Mixed heavy metal stress on photosynthesis, transpiration 
671

672

673 Chen, L.H., Han, Y., Jiang, H., Korpelainen, H., Li, C.Y., 2011. Nitrogen nutrient status

674 induces sexual differences in responses to cadmium in Populus yunnanensis. J. Exp.

675 Bot. 62, 5037-5050.

676

677 Chen, J., Duan, B.L., Wang, M.L., Korpelainen, H., Li, C.Y., 2014. Intra-and inter678 sexual competition of Populus cathayana under different watering regimes. Funct. Ecol. $67928,124-136$.

680

681

682

683

684

685

686

687

688

689

690

691

692

rate, and chlorophyll content in poplar hybrids. For. Sci. Technol. 12, 55-61.

$$
28,124-136 .
$$

Chen, J., Duan, B.L., Xu, G., Korpelainen, H., Niinemets, Ü., Li, C.Y., 2016. Sexual competition affects biomass partitioning, carbon-nutrient balance, $\mathrm{Cd}$ allocation and ultrastructure of Populus cathayana females and males exposed to Cd stress. Tree Physiol. 36, 1353-1368.

Chen, J., Han, Q.Q., Duan, B.L., Korpelainen, H., Li, C.Y., 2017. Sex-specific competition differently regulates ecophysiological responses and phytoremediation of Populus cathayana under Pb stress. Plant Soil 421, 203-218.

Duruibe, J.O., Ogwuegbu, M.O.C., Egwurugwu, J.N., 2007. Heavy metal pollution and human biotoxic effects. Inter. J. Physical. Sci. 2, 112-118. 
693

694

695

696

697

698

699

700

701

702

703

704

705

706

707

708

709

710

711

712

713

714

El Mehdawi, A.F., Quinn, C.F., Pilon-Smits, E.A., 2011. Effects of selenium hyperaccumulation on plant-plant interactions: evidence for elemental allelopathy?

New Phytol. 191, 120-131.

Ellis, R.J., Morgan, P., Weightman, A.J., Fry, J.C., 2003. Cultivation-dependent and independent approaches for determining bacterial diversity in heavy-metalcontaminated soil. Appl. Environ. Microbiol. 69, 3223-3230.

Fontana, A., Patrone, V., Puglisi, E., Morelli, L., Bassi, D., Garuti, M., Rossi, L., Cappa, F., 2016. Effects of geographic area, feedstock, temperature, and operating time on microbial communities of six full-scale biogas plants. Bioresource Technol. 218, 980990.

Guo, Q.X., Yan L.J., Korpelainen, H., Niinemets, Ü., Li C.Y., 2019. Plant-plant interactions and $\mathrm{N}$ fertilization shape soil bacterial and fungal communities. Soil Biol. Biochem. 128, 127-138.

Hawkins, A.P., Crawford, K.M., 2018. Interactions between plants and soil microbes may alter the relative importance of intraspecific and interspecific plant competition in a changing climate. AoB Plants 10, ply039.

He, J.L., Li, H., Luo, J., Ma, C.F., Li, S.J., Qu, L., et al., 2013a. A transcriptomic 
715

716

717

718

719

720

721

722

723

724

725

726

727

728

729

730

731

732

733

734

735

736

network underlies microstructural and physiological responses to cadmium in Populus $\times$ canescens. Plant Physiol. 162, 424-439.

He, J.L., Li, H., Ma, C.F., Zhang, Y.L., Polle, A., Rennenberg, H., Cheng, X.Q., Luo, Z.B., 2015a. Overexpression of bacterial r-glutamylcysteine synthetase mediates changes in cadmium influx, allocation and detoxification in poplar. New Phytol. 205, $240-254$.

He, J., Ma, C., Ma, Y., Li, H., Kang, J., Liu, T., Polle, A., Peng, C.H., Luo, Z.B., 2013 b. Cadmium tolerance in six poplar species. Environ. Sci. Pollut. R. 20, 163-174.

Hong, K., Gao, A.H., Xie, Q.Y., Gao, H.G., Zhuang, L., Lin, H.P., Yu, H.P., Li, J., Yao, X.S., Goodfellow, M., Ruan, J.S., 2009. Actinomycetes for marine drug discovery isolated from mangrove soils and plants in China. Mar. Drugs 7, 24-44.

Hou, D.D., Wang, K., Liu, T., Wang, H.X., Lin, Z., Qian, J., Lu, L.L., Tian, S.K., 2017. Unique rhizosphere micro-characteristics facilitate phytoextraction of multiple metals in soil by the hyperaccumulating plant Sedum alfredii. Environ. Sci. Technol. 51, 56755684.

Hou, D.D., Wang, R.Z., Gao, X.Y., Wang, K., Lin, Z., Ge, J., Liu, T., Wei, S., Chen, WK., Xie, RH., et al., 2018. Cultivar-specific response of bacterial community to 
737

738

739

740

741

742

743

744

745

746

747

748

749

750

751

752

753

754 755

756

757

758

cadmium contamination in the rhizosphere of rice (Oryza sativa L.). Environ. Pollut. $241,63-73$.

Hodge, A., Fitter, A.H., 2013. Microbial mediation of plant competition and community structure. Funct. Ecol. 27, 865-875.

Howard, R.J., Mendelssohn, I.A., 2000. Structure and composition of oligohaline marsh plant communities exposed to salinity pulses. Aquatic Bot. 68, 143-164.

Hu, W., Lu, Z., Meng, F., Li, X., Cong, R., Ren, T., Sharkey, T.D., Lu, J., 2020. The reduction in leaf area precedes that in photosynthesis under potassium deficiency: the importance of leaf anatomy. New Phytol. https://doi.org/10.1111/nph.16644.

Huang, S.H., 2014. Fractional distribution and risk assessment of heavy metal contaminated soil in vicinity of a lead/zinc mine. T. Nonferr. Metal. 24, 3324-3331.

Juvany, M., Munné-Bosch, S., 2015. Sex-related differences in stress tolerance in dioecious plants: a critical appraisal in a physiological context. J. Exp. Bot. 66, 60836092.

Ke, P.J., Wan, J., 2020. Effects of soil microbes on plant competition: a perspective from modern coexistence theory. Ecol. Monogr. 90, 1391. 
760 Koelbener, A., Ramseier, D., Suter, M., 2008. Competition alters plant species response 761 to nickel and zinc. Plant Soil 303, 241-251.

762

763

Langille, M.G.I., Zaneveld, J., Caporaso, J.G., McDonald, D., Knights, D., Reyes, J.A.,

Clemente, J.C., Burkepile, D.E., Thurber, R.L.V., Knight, R., Beiko, R.G., Huttenhower,

C., 2013. Predictive functional profiling of microbial communities using 16S rRNA marker gene sequences. Nature Biotech. 31, 814-821.

767

Li, X.Q., Meng, D.L., Li, J., Yin, H.Q., Liu, H.W., et al., 2017. Response of soil microbial communities and microbial interactions to long-term heavy metal contamination. Environ. Pollut. 231, 908-917.

771

772 Li, Y., Duan, B.L., Chen, J., Korpelainen, H., Niinemets, Ü., Li, C.Y., 2016. Males 773 exhibit competitive advantages over females of Populus deltoides under salinity stress. 774 Tree Physiol. 36, 1573-1584.

775

776 Liu, M., Bi, J.W., Liu, X.C., Kang, J.Y., Korpelainen, H., Niinemets, Ü., Li, C.Y., 2020a.

777 Microstructural and physiological responses to cadmium stress under different nitrogen 778 levels in Populus cathayana females and males. Tree Physiol. 40, 30-45. 
781

782

783

784

785

786

787

788

789

790

791

792

793

794

795

796

797

798

799

800

801

802

of Populus cathayana differentially sensitive to Cd stress? J. Hazard. Mater. 25, 122411.

Lu, L.L., Tian, S.K., Zhang, J., Yang, X.E., Labavitch, J.M., Webb, S.M., Latimer, M., Brown, P.H., 2013. Efficient xylem transport and phloem remobilization of $\mathrm{Zn}$ in the hyperaccumulator plant species Sedum alfredii. New Phytol. 198, 721-731.

Marasco, R., Mosqueira, M.J., Fusi, M., Ramond, J.B., Merlino, G., Booth, J.M., Daffonchio, D., 2018. Rhizosheath microbial community assembly of sympatric desert speargrasses is independent of the plant host. Microbiome 6, 215.

Mercer, C.A., Eppley, S.M., 2010. Inter-sexual competition in a dioecious grass.

Oecologia 164, 657-664.

Merloti, L.F., Mendes, L.W., Pedrinho, A., de Souza, L.F., Ferrari, B.M., Tsai, S.M., 2019. Forest-to-agriculture conversion in Amazon drives soil microbial communities and N-cycle. Soil Biol. Biochem. 137, 107567.

Mishra, J., Singh, R., Arora, N.K., 2017. Alleviation of heavy metal stress in plants and remediation of soil by rhizosphere microorganisms. Front. Microbiol. 8, 1706.

Navarro-Noya, Y.E., Jan-Roblero, J., del Carmen González-Chávez, M., HernándezGama, R., Hernández-Rodríguez, C., 2010. Bacterial communities associated with the 
803

804

805

806

807

808

809

810

811

812

813

814

815

816

817

818

819

820

821 lux biosensor for estimating bioavailable mercury in soil. Soil Biol. Biochem. 32, 639-

822 646.

823

824 Salisbury, A.B., Gallagher F.J., Caplan J.S., Grabosky J.C., 2018. Maintenance of

rhizosphere of pioneer plants (Bahia xylopoda and Viguiera linearis) growing on heavy metals-contaminated soils. Antonie Van Leeuwenhoek 97, 335-349.

Parks, D.H., Tyson, G.W., Hugenholtz, P., Beiko, R.G., 2014. STAMP: statistical analysis of taxonomic and functional profiles. Bioinformatics 30, 3123-3124.

Pilon-Smits, E.A., Freeman, J.L., 2006. Environmental clean up using plants: biotechnological advances and ecological considerations. Front. Ecol. Environ. 4, 203210.

Pishchik, V.N., Vorob’ev, N.I., Provorov, N.A., Khomyakov, Y.V., 2016. Mechanisms of plant and microbial adaptation to heavy metals in plant-microbial systems. Microbiol. $85,257-271$.

Rajkumar, M., Sandhya, S., Prasad, M.N.V., Freitas, H., 2012. Perspectives of plantassociated microbes in heavy metal phytoremediation. Biotech. Adv. 30, 1562-1574.

Rasmussen, L.D., Sørensen, S.J., Turner, R.R., Barkay, T., 2000. Application of a mer- 
825

826

827

828

829

830

831

832

833

834

835

836

837

838

839

840

841

842

843

844

photosynthesis by Betula populifolia in metal contaminated soils. Sci. Total Environ. $625,1615-1627$.

Sánchez-Vilas, J., Turner, A., Pannell, J.R., 2011. Sexual dimorphism in intra and interspecific competitive ability of the dioecious herb Mercurialis annua. Plant Biol. $13,218-222$.

Shi, G.R., Liu, C.F., Cai, Q.S., Liu, Q.Q., Hou, C.P., 2010. Cadmium accumulation and tolerance of two safflower cultivars in relation to photosynthesis and antioxidantive enzymes. Bull Environ. Contam. Toxicol. 85, 256-263.

Siciliano, S.D., Palmer, A.S., Winsley, T., Lamb, E., Bissett, A., Brown, M.V., van Dorst, J., Ji, M., Ferrari, B.C., Grogan, P., Chu, H., 2014. Soil fertility is associated with fungal and bacterial richness, whereas $\mathrm{pH}$ is associated with community composition in polar soil microbial communities. Soil Biol. Biochem. 78, 10-20.

Simkin, A.J., López-Calcagno, P.E., Raines, C.A., 2019. Feeding the world: improving photosynthetic efficiency for sustainable crop production. J Exp Bot. 70, 1119-1140.

Tao, Q., Zhao, J., Li, J., Liu, Y., Luo, J., Yuan, S., Li, B., Li, Q., Xu, Q., Yu, X., Huang, H. 2020. Unique root exudate tartaric acid enhanced cadmium mobilization and uptake in Cd-hyperaccumulator Sedum alfredii. J. Hazard. Mater. 383, 121177. 
848 Tian, Y., Gao, L., 2014. Bacterial diversity in the rhizosphere of cucumbers grown in 849 soils covering a wide range of cucumber cropping histories and environmental 850 conditions. Microb. Ecol. 68, 794-806.

851

852 Tokalıŏglu, Ş., Çiçek, B., İnanç, N., Zararsız, G., Öztürk, A., 2018. Multivariate 853 statistical analysis of data and ICP-MS determination of heavy metals in different 854 brands of spices consumed in Kayseri, Turkey. Food Anal. Method. 11, 2407-2418.

855

856 Tonnabel, J., David, P., Pannell, J.R., 2017. Sex-specific strategies of resource 857 allocation in response to competition for light in a dioecious plant. Oecologia $185,675-$ $858 \quad 686$.

859

860 Tonneijck, A.E., Franzaring, J., Brouwer, G., Metselaar, K., Dueck, T.A., 2004. Does 861 interspecific interaction alter effects of early season ozone exposure on plants from wet 862 grasslands? Results of a three-year experiment in open-top chambers. Environ. Pollut. $863 \quad 31,205-213$.

864

865 Van Kooten, O., Snel, J.F., 1990. The use of chlorophyll fluorescence nomenclature in 866 plant stress physiology. Photosyn. Res. 25, 147-150.

867

868 Van der Meij, A., Willemse, J., Schneijderberg, M.A., Geurts, R., Raaijmakers, J.M., 
869

870

871

872

873

874

875

876

877

878

879

880

881

882

883

884

885

886

887 Wood, J.L., Tang, C., Franks, A.E., 2016. Microbial associated plant growth and heavy

888

889

890

van Wezel, G.P., 2018. Inter-and intracellular colonization of Arabidopsis roots by endophytic actinobacteria and the impact of plant hormones on their antimicrobial activity. Antonie van Leeuwenhoek 111, 679-690.

Varga, S., Vega-Frutis, R., Kytöviita, M.M., 2017. Competitive interactions are mediated in a sex-specific manner by arbuscular mycorrhiza in Antennaria dioica. Plant Biol. 19, 217-226.

Viaene, T., Langendries, S., Beirinckx, S., Maes, M., Goormachtig, S., 2016. Streptomyces as a plant's best friend? FEMS Microbiol. Ecol. 92, fiw119.

Watve, M.G., Tickoo, R., Jog, M.M., Bhole, B.D., 2001. How many antibiotics are produced by the genus Streptomyces? Arch. Microbiol. 176, 386-390.

Weng, H.X., Ma X.W., Fu, F.X., Zhang, J.J., Liu, Z., Tian, L.X., Liu, C., 2014. Transformation of heavy metal speciation during sludge drying: mechanistic insights. J. Hazard. Mater. 265, 96-103. metal accumulation to improve phytoextraction of contaminated soils. Soil Biol. Biochem. 103, 131-137. 
891

892

893

894

895

896

897

898

899

900

901

902

903

904

905

906

907

908

909

910

911

912

Xia, Z.C., He, Y., Yu, L, Lv, R.B., Korpelainen, H., Li, C.Y., 2020. Sex-specific strategies of phosphorus (P) acquisition in Populus cathayana as affected by soil $\mathrm{P}$ availability and distribution. New Phytol. 225, 782-792.

Xie, Q., Gui, D., Liu, W., Wu, Y., 2020. Risk for Indo-Pacific humpback dolphins

(Sousa chinensis) and human health related to the heavy metal levels in fish from the Pearl River Estuary, China. Chemosphere 240: 124844.

Yuan, J., Zhao, J., Wen, T., Zhao, M., Li, R., Goossens, P., Huang, Q., Bai, Y., Vivanco, J.M., Kowalchuk, G.A., Berendsen, R.L., 2018. Root exudates drive the soil-borne legacy of aboveground pathogen infection. Microbiome 6, 1-2.

Zhang, S., Tang, D.T., Korpelainen, H., Li, C.Y., 2019. Metabolic and physiological analyses reveal that Populus cathayana males adopt an energy-saving strategy to cope with phosphorus deficiency. Tree Physiol. 39, 1630-1645.

Zhao, H., Li, Y, Zhang, X.L., Korpelainen, H., Li, C.Y., 2012. Sex-related and stagedependent source- to-sink transition in Populus cathayana grown at elevated $\mathrm{CO}_{2}$ and elevated temperature. Tree Physiol. 32, 1325-1338.

Zhao, Z., Shi, H.J., Kang, X.J., Liu, C.Q., Chen, L.C., Liang, X.F., Jin, L., 2017. Interand intra-specific competition of duckweed under multiple heavy metal contaminated 
913 water. Aquatic Toxicol. 192, 216-223.

914

915 Zloch, M., Thiem, D., Gadzała-Kopciuch, R., Hrynkiewicz, K., 2016. Synthesis of

916 siderophores by plant-associated metallotolerant bacteria under exposure to $\mathrm{Cd}^{2+}$.

917 Chemosphere 156, 312-325. 


\section{Figure legends}

Fig 1. Zinc (Zn) accumulation in leaves (a), stems (b) and roots (c), translocation factor ( $\left.T_{\mathrm{f}}\right)(\mathrm{d})$, the root bio-concentration factor $(\mathrm{BCF})(\mathrm{e})$ and shoot BCF (f) in P. cathayana females and males under different cultivation patterns and excess $\mathrm{Zn}$. Values are expressed as means $\pm \mathrm{SD}(n=4)$. Different letters represent significant differences between treatments $(P<0.05)$. F, female; $\mathrm{M}$, male; F/FF, female under intrasexual interaction; $\mathrm{M} / \mathrm{FM}$, male under intersexual interaction; $\mathrm{M} / \mathrm{MM}$, male under intrasexual interaction; F/FM, female under intersexual interaction.

Fig 2. Taxonomic compositions of bacterial communities in the rhizospheres of $P$. cathayana females and males at the phylum level with the relative abundance over $1 \%$ under excess zinc (Zn). Rhizospheric soil samples from plants under single-sex (a) and double-sex interactions (b). Average relative abundance of key phyla in the rhizospheric soil from plants under single-sex (c) and double-sex interactions (d); FF, female with intrasexual interaction; $\mathrm{FF}+\mathrm{Zn}$, FF with excess $\mathrm{Zn}$; FM, female and male under intersexual interaction; FM+Zn, FM with excess $\mathrm{Zn}$; MM, male with intrasexual interaction; MM+Zn, MM with excess Zn. A, Proteobacteria; B, Actinobacteria; C,

Chloroflexi; D, Acidobacteria; E, Planctomycetes; F, Bacteroidetes; G, Gemmatimonadetes.

Fig 3. Box plots for alpha diversity (effective number of species) (a, b) and beta- 
diversity (principal co-ordinates analysis) of bacteria from the rhizospheric soil of $P$.

941 cathayana females and males under excess zinc $(\mathrm{Zn})$ treatment. Alpha diversity of 942 bacteria from the rhizospheric soil of plants under single-sex (a) and double-sex 943 interaction (b). Principal coordinate analysis plots among bacterial communities in the 944

945 double-sex interactions (d). F/FM, female under intersexual interaction; M/FM, male 946 under intersexual interaction; FF, female under intersexual interaction; MM, male under 947 intrasexual interaction.

948

949 Fig 4. LEfSe used to identify abundant taxa in the rhizospheric soil from P. cathayana 950 females and males under excess zinc (Zn) treatment. A cladogram was generated by 951 LEfSe indicating differences between bacteria at phylum, class, family and genus levels 952 953 954 955 956 control soil, irrespective of sex and interaction (c), and between interaction modes, 957 irrespective of $\mathrm{Zn}$ treatment (d). The node colour indicates taxa enriched under different 958 treatment and interaction patterns. Only taxa with LDA over 3 are shown. FF, female 959 under intrasexual interaction; FM, female and male under intersexual interaction; MM, 960 male under intrasexual interaction. 
Fig 5. Predicted functions of the bacterial communities from the rhizospheric soil of $P$.

963 cathayana females and males under excess zinc ( $\mathrm{Zn}$ ) treatment. Predicted functions of 964 the bacterial communities from the rhizospheric soil of plants from single sex (a) and 965 double-sexual interactions (b). F, female; F+Zn, F with excess Zn; M, male; $M+Z n, M$ 966 with excess Zn; F/FM, females under intersexual interaction; M/FM, male under 967 intersexual interaction; FF, female under intrasexual interaction; $\mathrm{FF}+\mathrm{Zn}$, FF with excess $968 \mathrm{Zn} ; \mathrm{MM}$, male under intrasexual interaction; $\mathrm{MM}+\mathrm{Zn}$, male under intrasexual 969 interaction.

970

971 Fig 6. Heatmaps of the average relative abundance of key bacteria at the genus level 972 positively (a) or negatively associated (b) with $\mathrm{Zn}$ levels in roots of $P$. cathayana 973 females and males exposed to different interaction patterns $(P<0.05)$. F, female; $\mathrm{M}$, 974 male; FF, female exposed to intrasexual interaction; M/FM, male exposed to intersexual 975 interaction; MM, male exposed to intrasexual interaction; F/FM, female exposed to 976 intersexual interaction. 
Table 1 Net photosynthesis rate $(A)$, stomatal conductance $\left(g_{s}\right)$, and fluorescence parameters $F v / F m, E T R, Y(I I)$ and $Y$ (NPQ) of $P$. cathayana females and males exposed to different sexual interactions under control conditions or excess zinc $(\mathrm{Zn}) . F_{\mathrm{v}} / F_{\mathrm{m}}$, maximum quantum efficiency of PS II photochemistry; ETR, electron transport rate; $Y(N P Q)$, quantum yield of regulated non-photochemical energy loss in $P S I I$; $Y(I I)$, quantum yield of photochemical energy conversion in PS II.

\begin{tabular}{lllllll}
\hline Treatment & $\boldsymbol{A}\left(\boldsymbol{\mu} \boldsymbol{m o l} \boldsymbol{m}^{-2} \boldsymbol{s}^{-1}\right)$ & $\boldsymbol{g}_{\mathbf{s}}\left(\boldsymbol{m o l} \boldsymbol{m}^{-2} \boldsymbol{s}^{-1}\right)$ & $\boldsymbol{F}_{\mathbf{v}} / \boldsymbol{F}_{\mathbf{m}}$ & $\boldsymbol{E T R}$ & $\boldsymbol{Y}(\boldsymbol{I I})$ & $\boldsymbol{Y}(\boldsymbol{N P Q})$ \\
\hline Control & & & & & & \\
F & $19.21 \pm 0.35 \mathrm{~d}$ & $0.24 \pm 0.02 \mathrm{f}$ & $0.79 \pm 0.01 \mathrm{~cd}$ & $51.48 \pm 0.52 \mathrm{abc}$ & $0.45 \pm 0.04 \mathrm{bc}$ & $0.28 \pm 0.01 \mathrm{fg}$ \\
M & $23.31 \pm 1.41 \mathrm{a}$ & $0.36 \pm 0.03 \mathrm{~b}$ & $0.81 \pm 0.00 \mathrm{a}$ & $52.88 \pm 2.85 \mathrm{ab}$ & $0.44 \pm 0.02 \mathrm{~cd}$ & $0.33 \pm 0.01 \mathrm{de}$ \\
F/FM & $19.11 \pm 0.27 \mathrm{~d}$ & $0.29 \pm 0.00 \mathrm{de}$ & $0.80 \pm 0.01 \mathrm{bc}$ & $49.10 \pm 3.12 \mathrm{~cd}$ & $0.44 \pm 0.02 \mathrm{~cd}$ & $0.27 \pm 0.11 \mathrm{fg}$ \\
M/FM & $22.49 \pm 0.26 \mathrm{~b}$ & $0.41 \pm 0.01 \mathrm{a}$ & $0.80 \pm 0.01 \mathrm{abc}$ & $54.4 \pm 2.20 \mathrm{a}$ & $0.49 \pm 0.01 \mathrm{a}$ & $0.26 \pm 0.01 \mathrm{fg}$ \\
F/FF & $22.15 \pm 0.93 \mathrm{ab}$ & $0.36 \pm 0.01 \mathrm{~b}$ & $0.80 \pm 0.01 \mathrm{bc}$ & $51.93 \pm 1.86 \mathrm{abc}$ & $0.48 \pm 0.02 \mathrm{ab}$ & $0.28 \pm 0.02 \mathrm{f}$ \\
M/MM & $21.64 \pm 0.48 \mathrm{~b}$ & $0.34 \pm 0.03 \mathrm{bc}$ & $0.81 \pm 0.01 \mathrm{ab}$ & $54.83 \pm 2.35 \mathrm{a}$ & $0.50 \pm 0.01 \mathrm{a}$ & $0.28 \pm 0.01 \mathrm{fg}$ \\
Zn treatment & & & & & \\
F & $13.73 \pm 0.40 \mathrm{f}$ & $0.20 \pm 0.01 \mathrm{~g}$ & $0.75 \pm 0.02 \mathrm{f}$ & $32.23 \pm 2.21 \mathrm{~g}$ & $0.23 \pm 0.01 \mathrm{i}$ & $0.49 \pm 0.02 \mathrm{a}$ \\
M & $18.94 \pm 0.01 \mathrm{e}$ & $0.28 \pm 0.03 \mathrm{e}$ & $0.78 \pm 0.00 \mathrm{~d}$ & $43.78 \pm 1.12 \mathrm{e}$ & $0.40 \pm 0.02 \mathrm{e}$ & $0.35 \pm 0.01 \mathrm{~cd}$ \\
F/FM & $18.11 \pm 0.27 \mathrm{e}$ & $0.23 \pm 0.02 \mathrm{fg}$ & $0.76 \pm 0.01 \mathrm{e}$ & $36.88 \pm 3.59 \mathrm{f}$ & $0.27 \pm 0.04 \mathrm{~h}$ & $0.36 \pm 0.04 \mathrm{c}$ \\
M/FM & $20.12 \pm 0.26 \mathrm{c}$ & $0.32 \pm 0.02 \mathrm{~cd}$ & $0.80 \pm 0.01 \mathrm{bcd}$ & $50.68 \pm 1.92 \mathrm{bc}$ & $0.41 \pm 0.02 \mathrm{de}$ & $0.25 \pm 0.03 \mathrm{~g}$ \\
F/FF & $19.77 \pm 0.86 \mathrm{~cd}$ & $0.25 \pm 0.04 \mathrm{f}$ & $0.79 \pm 0.00 \mathrm{~d}$ & $44.33 \pm 1.36 \mathrm{e}$ & $0.32 \pm 0.03 \mathrm{~g}$ & $0.45 \pm 0.04 \mathrm{~b}$ \\
M/MM & $18.15 \pm 0.10 \mathrm{e}$ & $0.15 \pm 0.02 \mathrm{~h}$ & $0.78 \pm 0.01 \mathrm{~d}$ & $47.00 \pm 1.43 \mathrm{de}$ & $0.36 \pm 0.01 \mathrm{f}$ & $0.32 \pm 0.02 \mathrm{e}$ \\
\hline
\end{tabular}

F, female; M, male; FF, female exposed to intrasexual interaction; M/FM, male exposed to intersexual interaction; MM, male exposed to intrasexual interaction; F/FM, female exposed to intersexual interaction; Different letters represent significant differences between treatments $(P<0.05)$. Values are means $\pm \mathrm{SE}(n=4)$. 
Table 2 PERMANOVA results using Bray-Curtis as a distance metric.

\begin{tabular}{lllll}
\hline Factor & \% explained & $F$ & $\mathrm{R}^{2}$ & $P$ \\
\hline Plantation modes & 25 & 4.38 & 0.25 & $0.001^{* * *}$ \\
Zn & 5 & 3.49 & 0.05 & $0.004^{* *}$ \\
Sex & 5 & 3.19 & 0.05 & $0.006^{* *}$ \\
Sex : Zn & 2 & 1.28 & 0.02 & 0.227 \\
Plantation modes : Zn & 11 & 1.91 & 0.11 & $0.007^{* *}$ \\
Residuals & 52 & & 0.52 & \\
\hline
\end{tabular}

Plantation modes: F, M, F/FF, FM, M/MM; sex: F, M; Zinc, excess Zn treatment. * $0.01<P \leq 0.05 ; * * 0.001<P \leq 0.01 ; * * * P \leq 0.001$. 
Fig. 1
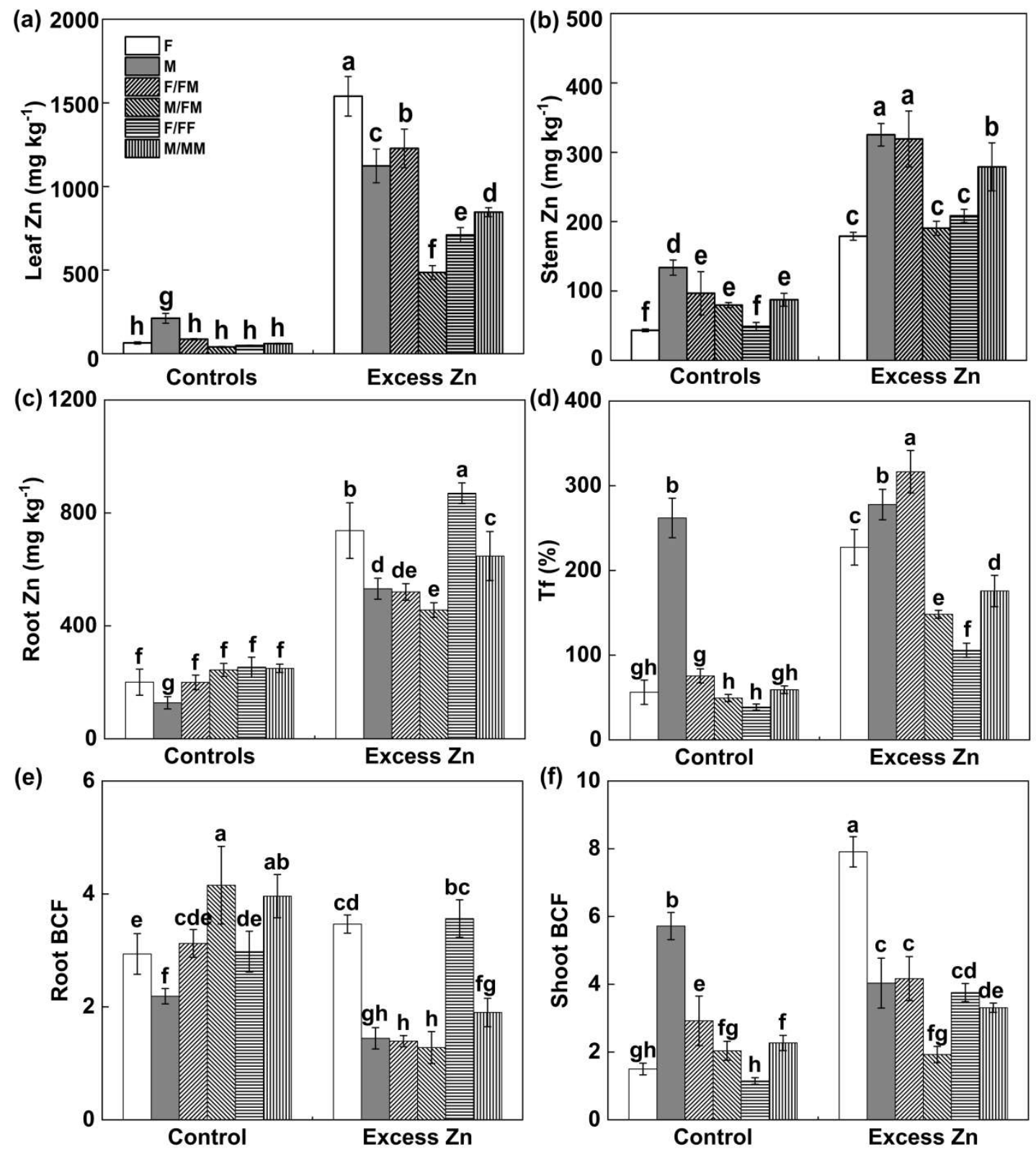
Fig. 2
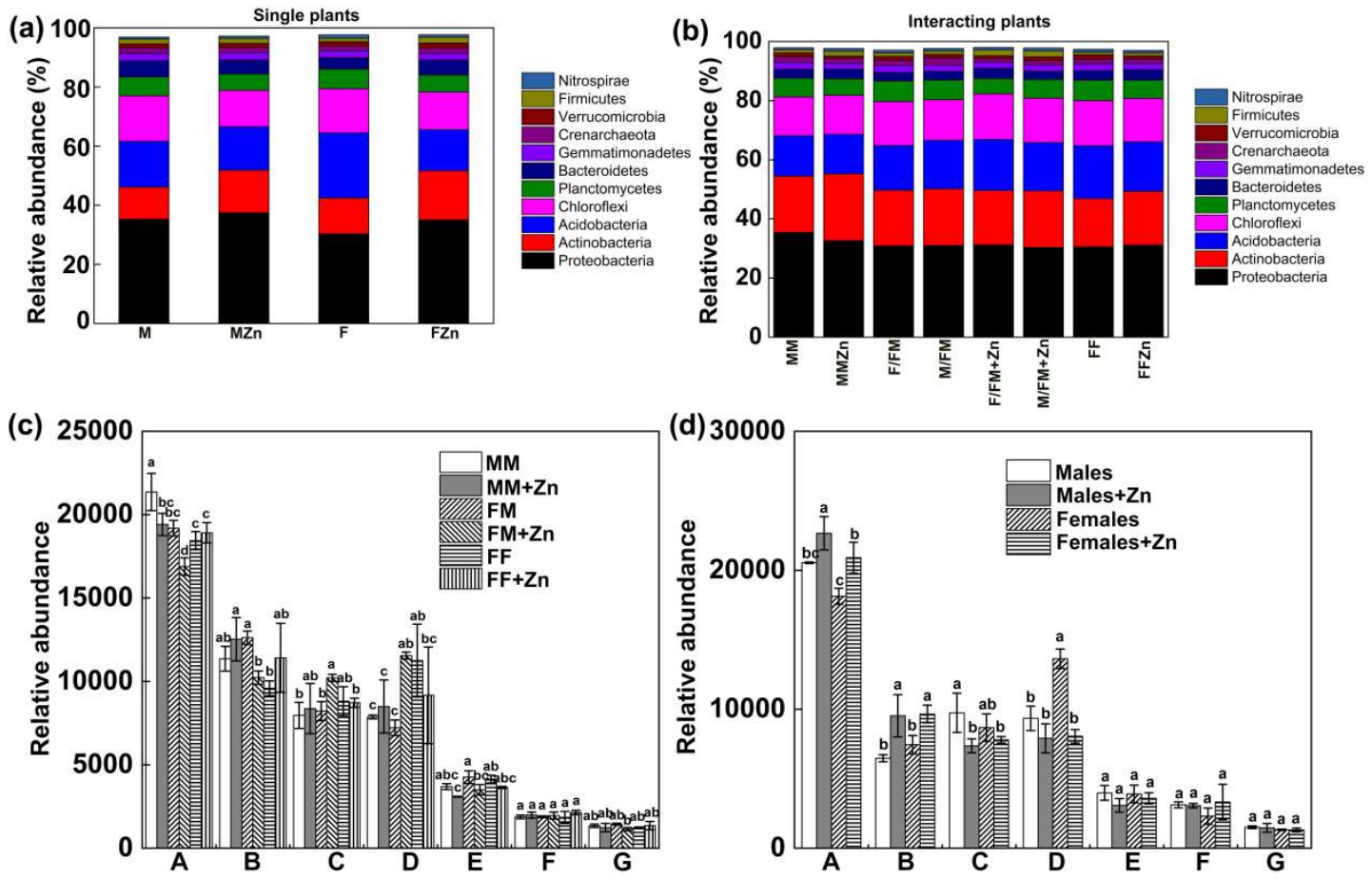
Fig. 3
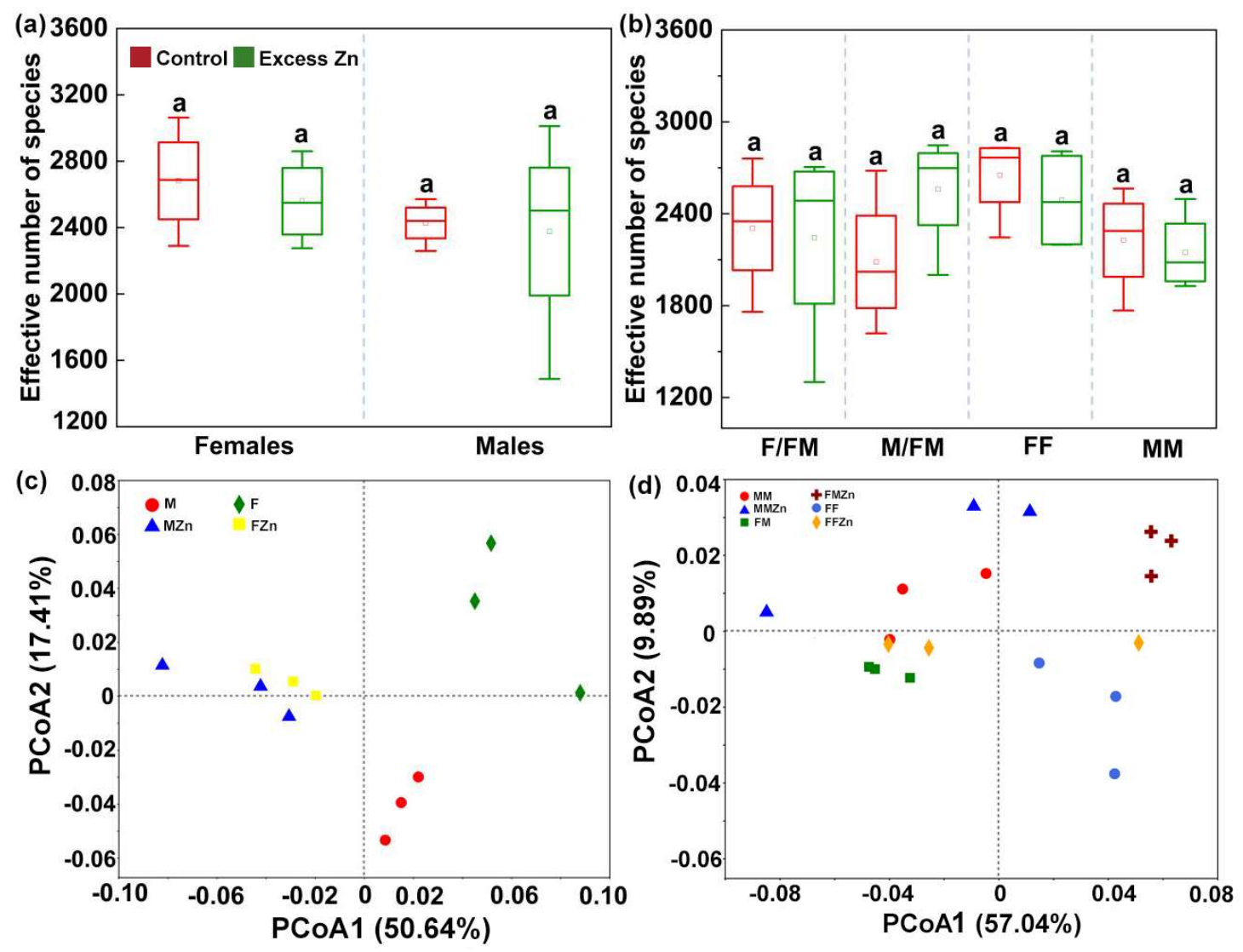
Fig. 4

(a)

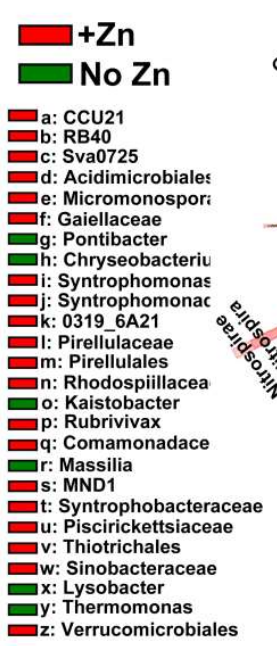

(c)

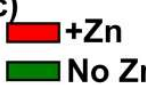

$\square$ a: CandidatusNitroso b: Nitrososhaeracea d: AKIW874 e: Cellulomonadacea f: Agromyces $\square \mathrm{h}:$ Mycobacterium i: Mycobacterium j: Rhodococcus k: Sporichthyacea I: Streptomyces m: Acti n: Solirubrobacterales

p: GCA004

r: JG30 KF_CM45

s: Bacillus

t: Rhodoplanes

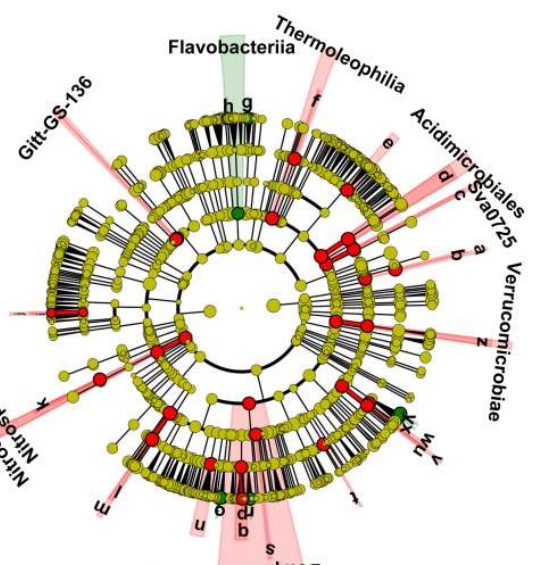

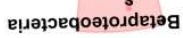

Saprospirae

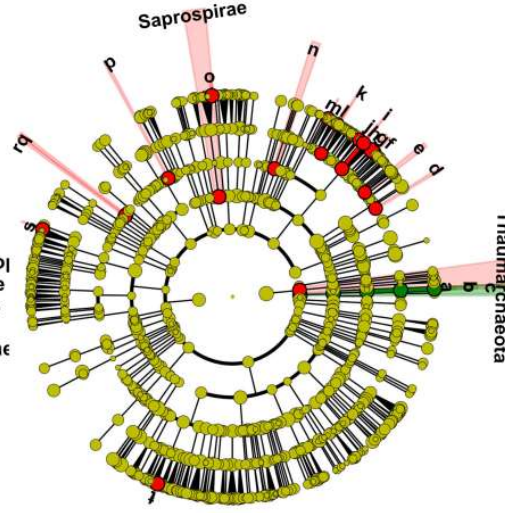

(b)

Saprospirae

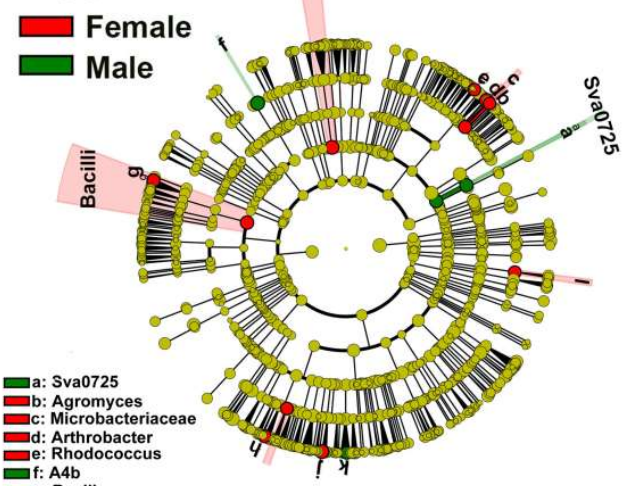

D: A4b

最: Devosia

j: Kaistobacter

|l: Verrucomicrob

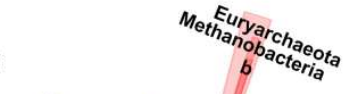

(d)
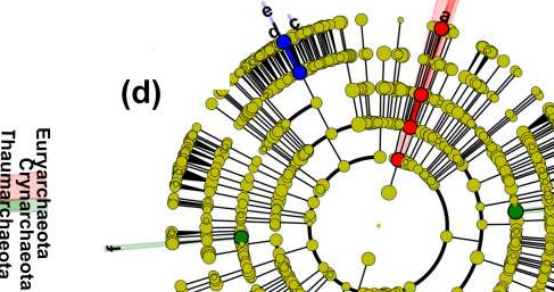

\section{$\square \mathrm{FF}$ \\ FM}

MM

a: Methanothermobacter

b: Methanobacteriales

c: Agromyces

e: Mycobacteriace

$\square$ f: Caldilineales 
Fig. 5

$95 \%$ confidence intervals (a) Peptidoglycan biosyntesis

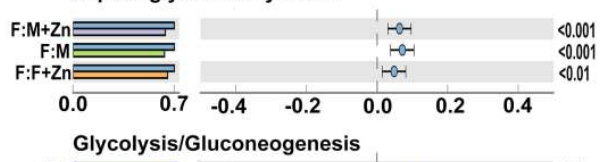

colysis/Gluconeogenesis
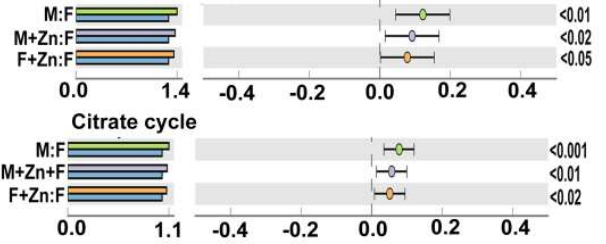

\begin{tabular}{lllllll}
\hline 0.0 & 1.1 & -0.4 & -0.2 & 0.0 & 0.2 & 0.4
\end{tabular}

Flavonoid biosynthesis

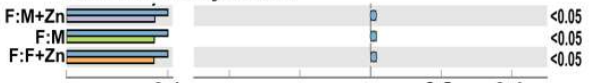

\begin{tabular}{lllllll}
\hline 0.0 & 0.1 & -0.4 & -0.2 & 0.0 & 0.2 & 0.4
\end{tabular}

Difference in proportions (\%)
$95 \%$ confidence intervals

Carotenoid biosynthesis
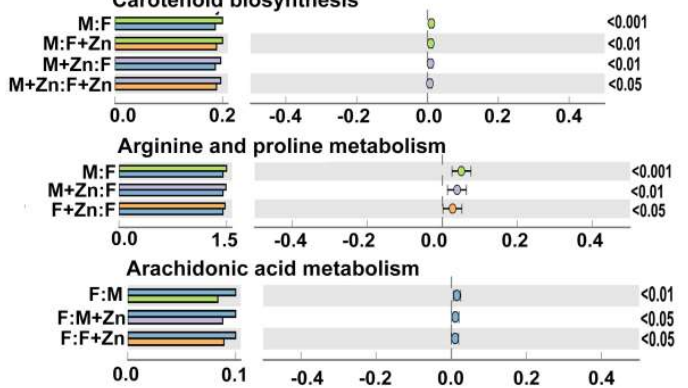

Valine, leucine and isoleucine biosynthesis

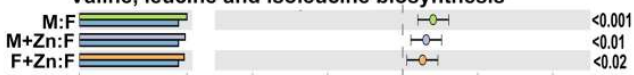

\begin{tabular}{lllllll}
\hline 0.0 & 1.0 & -0.4 & -0.2 & 0.0 & 0.2 & 0.4
\end{tabular}

Difference in proportions (\%)

(b) Cystine and methionine metabolism
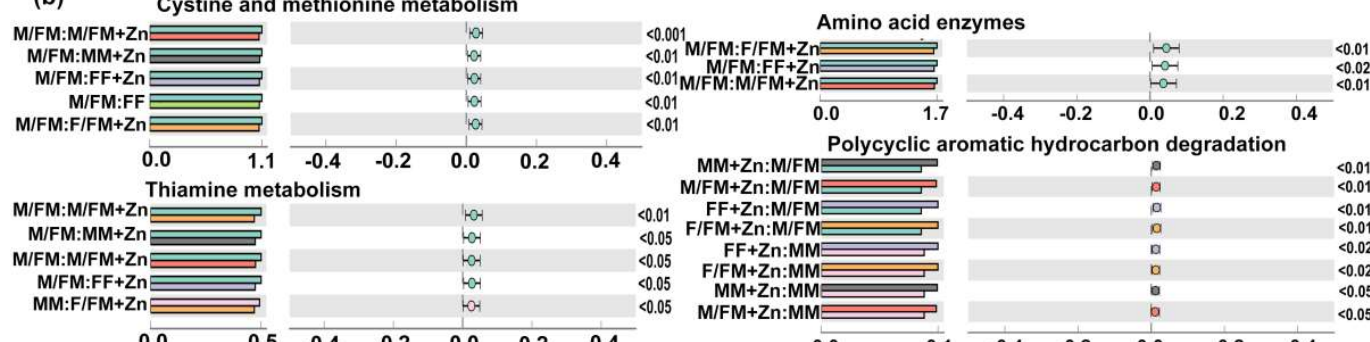

Tyrosine metabolism

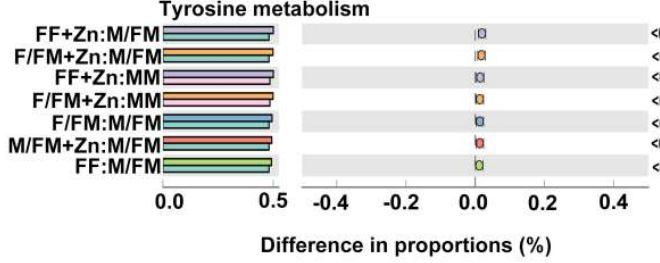

MM+Zn:M/FM Polycyclic aromatic hydrocarbon degradation

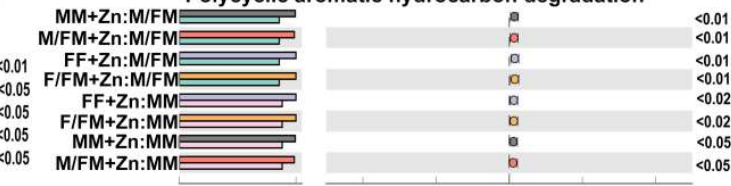

\begin{tabular}{llllll}
\hline 0.0 & 0.1 & 1 & 1 \\
\hline-0.4 & -0.2 & 0.0 & 0.2 & 0.4
\end{tabular}

$\begin{array}{lllllll}0.0 & 0.1 & -0.4 & -0.2 & 0.0 & 0.2 & 0.4\end{array}$

0.001 M/FM:M/FM+Zn Lipolic acid metabolism

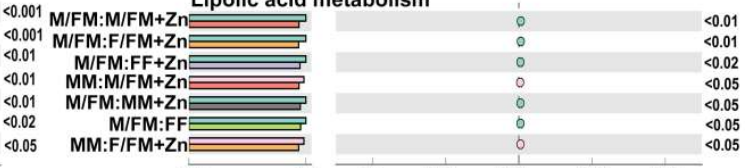

Difference in proportions $(\%)$

0.0

Difference in proportions (\%) 
Fig. 6

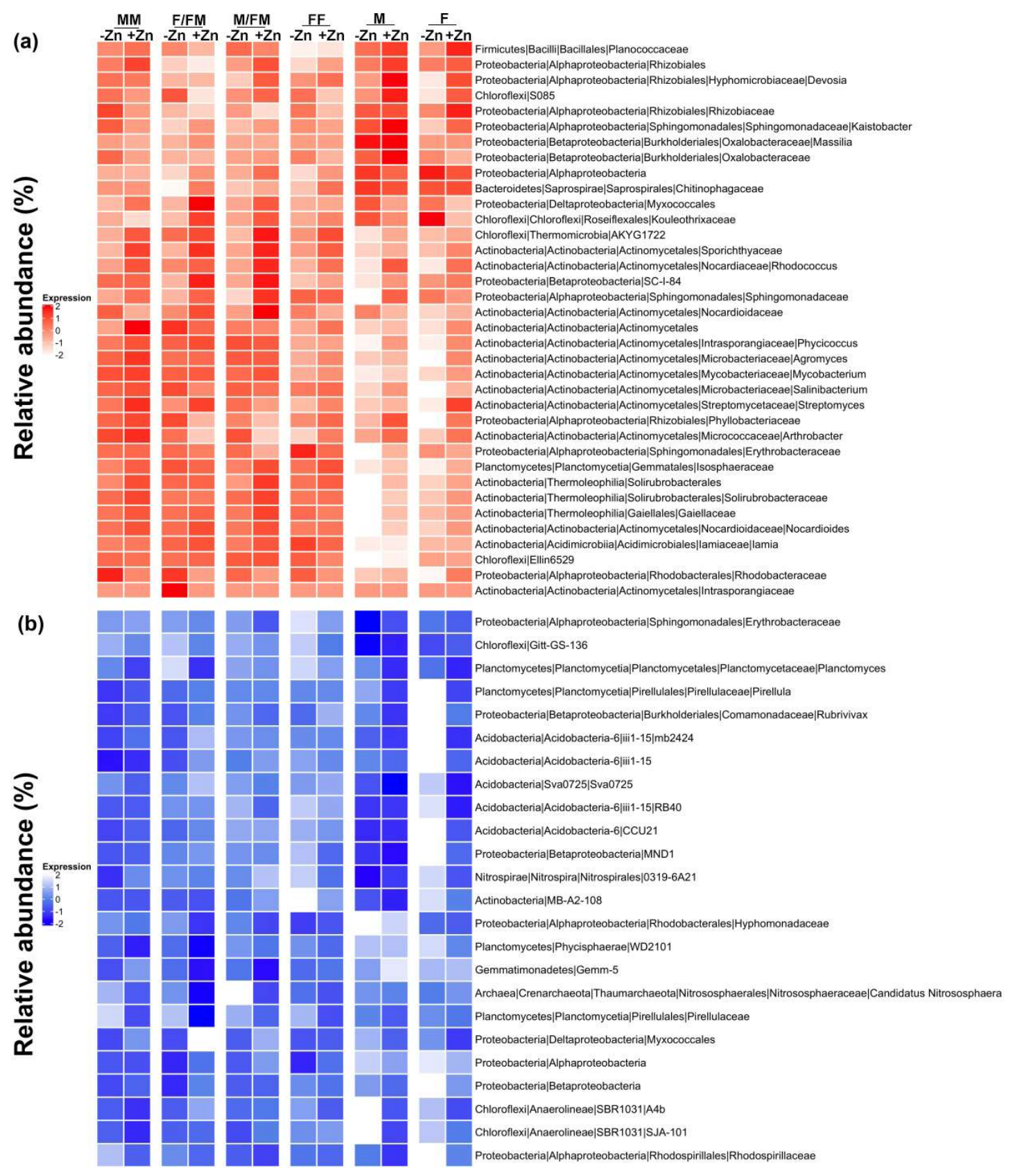

